\title{
Coastal Oceanographic Use of the U.S. Air Force Data Acquisition and Processing Program (DAPP)
}

\author{
by \\ OSCAR Karl Huh \\ Naval Oceanographic Office
}

September 1973

\section{Provisional Technical Report}
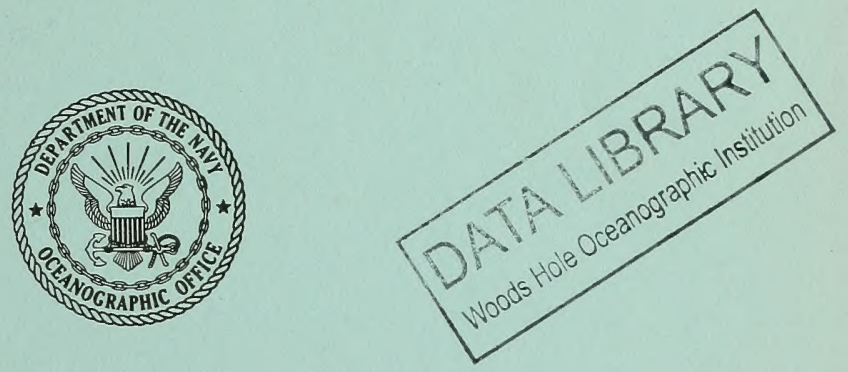

Prepared for the Office of Naval Research Under Task Number NR 387-062, Geography Program

(Code 414), Terrestrial Sciences Division 
o 10

wh Bast Regores<smiles>C1=CC2(CCC1)CCCC2</smiles> 


\begin{tabular}{|c|c|}
\hline REPORT DOCUMENTATION PAGE & $\begin{array}{l}\text { READ INSTRUCTIONS } \\
\text { BEFORE COMPLETING FORM }\end{array}$ \\
\hline $\begin{array}{l}\text { 1. REPORT NUMBER } \\
\text { TR-241 }\end{array}$ & 3. RECIPIENT'S CATALOG NUMBER \\
\hline $\begin{array}{l}\text { 4. TITLE (and subtite) } \\
\text { COASTAL OCEANOGRAPHIC USE OF THE U.S. AIR } \\
\text { FORCE DATA ACOUISITION AND PROCESSING }\end{array}$ & 5. TYPE OF REPORT \& PERIOD COVERED \\
\hline PROGRAM (DAPP) & 6. PERFORMING ORG. REPORT NUMBER \\
\hline $\begin{array}{l}\text { 7. AUTHOR(s) } \\
\text { Oscar K. Huh }\end{array}$ & 8. CONTRACT OR GRANT NUMBER(o) \\
\hline $\begin{array}{l}\text { 9. PERFORMING ORGANIZATION NAME AND ADDRESS } \\
\text { U.S. Naval Oceanographic Office } \\
\text { Washington, D.C. }\end{array}$ & $\begin{array}{l}\text { 10. PROGRAM ELEMENT, PROJECT, TASK } \\
\text { AREA Q WORK UNIT NUMBERS } \\
\text { NR } 387-062\end{array}$ \\
\hline \multirow[t]{2}{*}{$\begin{array}{l}\text { 11. CONTROLLING OFFICE NAME AND ADDRESS } \\
\text { Office of Naval Research }\end{array}$} & $\begin{array}{l}\text { 12. REPORT DATE } \\
\text { JanuarY } 1973\end{array}$ \\
\hline & $\begin{array}{l}\text { 13. NUMBER OF PAGES } \\
36\end{array}$ \\
\hline \multirow[t]{2}{*}{ 14. MONITORING AGENCY NAME \& ADDRESS(if different from Controlling Office) } & $\begin{array}{l}\text { 15. SECURITY CLASS. (of this roport) } \\
\text { Unclassified }\end{array}$ \\
\hline & $\begin{array}{l}\text { 15a. DECLASSIFICATION/DOWNGRADING } \\
\text { SCHEDULE }\end{array}$ \\
\hline
\end{tabular}

Approved for Public release: Distribution Unlimited.

17. DISTRIBUTION STATEMENT (ol the abstract entered in Block 20, $\|$ different from Report)

18. SUPPLEMENTARY NOTES

19. KEY WORDS (Continue on reverse side if necessary and Identify by block number)

20. ABSTRACT (Continue on reverse alde ! necessary and ldentify by block numbor)

The spaceborne infrared sensors $(8-13 \mu \mathrm{m})$ of the Air Force meteorological Data Acquisition and Processing Program (DAPP) have provided remarkable images of mesoscale sea surface thermal patterns outlining currents, thermally distinct watermasses, and oceanic fronts. During 1971-72 the thermal outlines of the South Korean Coastal Oceanic Front, the Tsushima Current, the Yellow Sea Warm Current, the China Coastal Current and the Liman Current were deterted and monitored with the 2 n.mi. resolution infrared DAPP imagery. The data are displayed in a

(Continued) 
20.

series of 16 gray shades on photograph-like images covering an area of $1560 \times 3000$ n.mi. of the earth's surface. The images are transverse mercator projections at scales of 1:15,000,000 or enlarged to $1: 7,500,000$ with a thermal resolution of $1.6^{\circ} \mathrm{C}$. The outstanding characteristic of this system are: 1 . the high repetition rate of coverage (minimum of four time daily), 2 . near real time data availability, 3 . high resolution ( $1 / 3$ and 2 n.mi.) visual and infrared images, and 4. the global coverage. As in other infrared systems, cloud cover prevents sea surface observations. The high repetition rate, however, increases the probability of obtaining clear sky conditions and most critically allows detection of rapid oceanic changes over large regions anywhere on the globe.

The availability of near real-time remotely sensed sea surface thermal data is a major breakthrough for oceanographic and other ocean operations. The system provides a synoptic sea surface thermal structure for direct incorporation into the conduct of operations within minutes of the satellite overpass. For example, DAPP operators, with HRIR data on effective radiation temperatures and thermal patterns of the sea, can provide search and rescue units information on water temperatures (survival times). In the case of ocean currents documented in marine atlases, they can also provide probable direction and speed of drift. In the case of Operation NUGGET RANCH (10 Oct. - 10 Nov., 1972) the synoptic HRIR data were used over the Sea of Japan to suppliment simultaneous surface measurements, for making decisions on spacing and positioning of ship tracks, to detect and position water masses, and to measure water mass boundary movements, rather than to substitute for standard oceanographic methods. Extensive aircraft, ship current meter and coastal observations were used to verify the oceanographic information content of these satellite observations. The field experiments clearly displayed the practical utility of both the DAPP and this entire approach to determining oceanic variability. In the end, the DAPP data were actually used to steer the entire oceanographic operation. It gave the near real-time synoptic overview, the optimum perspective for operational decision making. 
CONTENTS

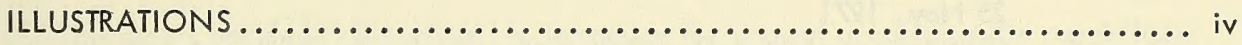

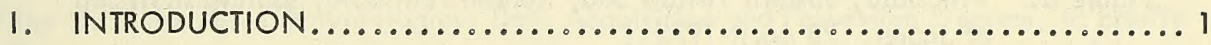

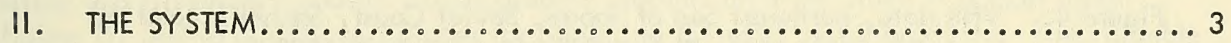

III. PROCEDURES FOR COASTAL OCEANOGRAPHIC USE............... 6

IV. ACKNOWLEDGEMENTS................................ 10

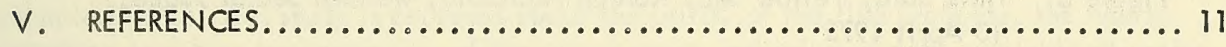

DISTRIBUTION LIST 


\section{LIST OF ILLUSTRATIONS}

Figure 1. Physical Oceanographic Features

Figure 2. VHR data, Yellow Sea, Korean Peninsula, and Western Sea of Japan. 25 Nov. 1971

Figure 3. VHR data, eastern Yellow Sea, Korean Peninsula, southwestern Sea of Japan. 28 April 1972

Figure 4. VHR data, northeast Sea of Japan, Soviet Coast, Sakhhlin, and the western portion of the Sea of Okhotsk. 13 April 1972

Figure 5. HRIR data, eastern Yellow Sea, Korean Peninsula, and western Sea of Japan. 28 April 1972

Figure 6. HRIR data, Yellow Sea, Korean Peninsula, western Sea of Japan. 10 April 1972

Figure 7. HRIR data, China Coastal Current in the Yellow Sea. 1 April 1972

Figure 8. HRIR data, East China Sea. 27 November 1971

Figure 9. HRIR data, the Tsushima Current, Korean Peninsula and western Sea of Japan. 27 Oct. 1972

Figure 10. Imagery of the South Coast of Korea. 10, 13, 27 Oct. 1972

Figure 11. Surface truth Oceanographic data. 16 Oct. 1972

Figure 12. DAPP temperature range setting for $\mathrm{MI} 1$ (16 gray shades). Display of HRIR data

Figure 13. Gray shade display of Sea Surface Thermal Structures 


\section{COASTAL OCEANOGRAPHIC USE OF THE U.S. AIR FORCE DATA ACQUISITION AND PROCESSING PROGRAM (DAPP)}

\section{INTRODUCTION}

This report has three objectives: to introduce the coastal oceanographic capabilities of the U.S. Air Force meteorological Data Acquisition and Processing Program, to briefly define and illustrate a coastal oceanographic problem area for which it is most useful (figure 1), and to outline techniques for obtaining the most useful products. The valuable characteristics of this remote sensing system are the global availability of high resolution ( $1 / 3$ and $2 \mathrm{n} . \mathrm{mi}$.) imagery, (figs. 2-10) the high repetition rate (minimum of 4 times daily), and the capability of the infrared sensors to detect thermally distinct surface waters and oceanic fronts. This study is centered about the utility of the film products, the nearly distortion free film transparencies of the visual range and infrared data available at scales of $1: 15,000,000$ and $1: 7,500,000$ in near real time.

A major problem in studies of narrow continental shelf regions of the globe is the detection and measurement of the influence of impinging offshore ocean currents on coastal waters. Permanent or semipermanent currents, the major circulation elements of adjacent ocean basins, are time-dependent features, meandering, repositioning, and even temporarily disappearing in the course of an experiment or survey. These currents have fundamental role as the major source of both seawater and energy to either flush the continental shelf of existing waters or drive the local coastal circulation. The position, orientation, structure and strength of gradients along the landward wall or coastal front of an ocean current, are key indicators of mixing processes and the effects of the impinging ocean current. These fronts, though difficult to observe or even detect by conventional methods, are shown to be readily detected and their movement in time and space easily followed by remote sensing methods.

Coastal fronts, and oceanic fronts in general, are important but poorly known structures in the sea. The term "oceanic front" has been widely adopted by the oceanographic community from analogy with atmospheric fronts (Griffiths, 1965). Uda (1938) in an early but most definitive paper delved deeply into the structure and origin of oceanic fronts as he sought to understand the nature and mechanism of their common surface effect, current rips or "siome". He defined the latter as "A comparatively narrow stretched band, which appears on the sea surface with singular rippling and is commonly accompanied by foams and other drifting-bodies of various kind..." coinciding with the line of discontinuity between two different watermasses or between currents. Uda classified siomes into three types: the first caused by pure convergence at the sea surface, the second by upwelling or divergence, and the third by strong current shear. He also reports that they frequently though not exclusively, occur near the margin of continental shelves and that they are commonly the sea surface expression of the contact of waters of different colors, chiefly yellow-green coastal waters and the deep blue-green oceanic water. Major ocean fronts are common in deep ocean areas, where they occur as boundary zones between major currents or water types (Defant, 1961, p. 453), Laevastu and Lafond, 1970). Griffiths (1965) proposed the term "frontal system" for the entire boundary between two kinds of 
water, reserving the word "front" for those small parts actually investigated. Since this study focuses on a particular kind of oceanic front, the term "coastal front" will be used for those oceanic fronts formed in the vicinity of coasts or continental shelves as a direct result of local circulation or ocean basin boundary zone effects. Coastal fronts are narrow linear zones with steep horizontal gradients of physical properties (temperature, salinity, density, transparency, or color) at the sea surface separating different water masses.

The availability of near real-time remotely sensed sea surface data on oceanic fronts and water masses to shipborne scientists is a major breakthrough in oceanographic operations. The areal extent, differences in sea state, sea surface temperature, and the frequent presence of slicks over oceanic fronts make them particularly excellent subjects for remote sensing methods in oceanography. Temperature differences are readily detectable by aircraft and satellite scanners. Coastal fronts with their turbidity/color as well as temperature gradients are detectable on visual-range as well as infrared band sensors of aircraft and spacecraft, making them prime targets for remote sensing methods. The near real-time synoptic data permit optimum use of ship time and a most complete grasp of the areal structure and time changes of the upper water column as expressed at the sea surface.

The need for synoptic temperature, salinity, and velocity data on the sea has been expressed previously perhaps most vividly by the following authors; Sverdrup, Johnson, and Fleming (1942) stated:

"In nature, laminar flow is rarely or never encountered, but instead turbulent flow or turbulence prevails. By turbulent flow is understood a state in which random motion of smaller or larger masses or the fluid is superimposed upon some simple pattern of flow... as a consequence a snap-shot of the instantaneous distribution of velocity, temperature, salinity, and other variables would show a most complicated pattern, but so far no means has been developed for establishing this picture."

In a study of the exchange of Gulf Stream Water with North Carolina Shelf Water in Onslow Bay, Blanton (1971) using hydrographic stations and single current meter mooring came to the following conclusion:

"I feel that very little can be gained by additional hydrographic data of the kind discussed here. We have a cursory understanding of the exchange process, but we are completely in the dark on the time and space scales involved. Do the intrusions begin as intense narrow currents at the shelf break that spread out once the water is forced onto the shelf? Do they occur, instead as a broad "upwelling" over long lengths of the edge of the shelf? How long does an intrusion last? What factors really govern it such as winds, state or shelf water, position of the Gulf Stream? How do intrusions of Virginian Coastal Water complicate the model presented here? It seems that all these questions are beyond the scope of traditional shipboard oceanography. Synoptic temperature and current data from key locations on the shelf are a logical next step in a study of continental shelf processes."

In Blanton's case, time lapse remote sensing of the fronts between Gulf Stream, Continental Slope, Virginia Coastal, and Carolina Shelf waters would be a major contribution to his 
study. Now one can obtain time lapse synoptic imagery of sea surface temperature and turbidity or color. Velocity might be derived from measurements of the displacement of identifiable parcels of water. Sea surface salinity can not be determined remotely at the present, but if salinities are associated with specific temperatures or turbidities they can be mapped and tracked in a given region.

\section{THE SYSTEM}

The U.S. Air Force System presently includes a classified space segment and several earth based segments. Data Acquisition and Processing Program (DAPP) is the Air Force land based segment consisting of a central acquisition and processing site and a number of air-transportable land-sites. The present Novy segment of this system will consist of two shipboard and two air-transportable land-based terminals next summer/fall followed by a new central data acquisition and processing site at Monterey next winter. As the Air Force and Navy earth-based segments bear a number of similarities the Air Force DAPP will be described. DAPP acquires, processes, displays and disseminates very high resolution remotely sensed data directly and on tape which is gathered from space. The Air Force as lead agency has provided the following information and specifications necessary for data utilization on anclassified basis.

The sensors of the present system are mounted on two sophisticated satellites in near-polar, sun-synchronous orbits at $450 \mathrm{n}$.mi. altitudes. The nodes (equatorial crossings) are ascending south to north on the daytime side of the earth and descending on the nightime side. The orbital period is about $100 \mathrm{~min}$. and the satellites step around the equator at $25^{\circ}$-longitude increments each successive nodal crossing. The spaceborne segment of the system consists of scanning infrared sensors operating in the spectral range of $8.0-13.0 \mu \mathrm{m}$ and video (visual range) sensors in the 0.4-1.1 $\mu \mathrm{m}$ range. The infrared sensors scan the earth and it atmosphere, recording the total effective blackbody emittance reaching satellite at the $450 \mathrm{n}$. mi . distance in space. The visual sensors receive brightness levels of reflected solar illumination to transmit albedo of the earth within the spectral range sensed. Both visual and infrared data are available as photograph-like imagery at 2 or $1 / 3$ nautical mile maximum resolution formats, in near real-time. The field of view of the scanning sensors gives a swath width of $1560 \mathrm{n}$.mi. for each pass. In addition to the picture-like imagery, an 8-channel radiometer, furnishes the DAPP with vertical temperature profiles of the atmosphere. The sensors and spacecraft are designed to be capable of functioning at any local sun time. The DAPP receives spacecraft data sensed near dawn near noon, early evening, and near midnight local sun time anywhere around the globe.

The DAPP satellite data are transmitted to earth via high speed (wide-band) data-links. There are two kinds of receiving sites, permanent receiving sites in the United States that relay data to the Air Force Global Weather Central, and mobile remote receiving sites for direct local readout, transportable anywhere in the world. The mobile site equipments including the tracking and receiving antenna, are contained in vans, for air or ship transportability. The permanent receiving sites acquire tape recorded satellite data for the entire globe encircling orbit, a $1560 \mathrm{n}$.mi. swath in a near polar orientation. The remotesite receiver acquires only a direct readout of about a $3000 \mathrm{n}$. mi. segment of an orbit as the satellite passes within line-of-sight. The Navy will add two shipboard readout mobile 
recievers to fleet units, two more land based mobile receivers, plus a large central processing site next year. The images presented in this report are exclusively from the mobile remotesite receivers.

The sensors consist of two scanning radiometers. One is a two channel scanning radiometer for high resolution visual data (HR) and for high resolution infrared data (HRIR). It employs one scanning mirror and a beam splitter which separates the incoming radiation by allowing transmission of visual radiation (HR .4-1.1 $1 \mu \mathrm{m}$ ) and reflection of the infrared (HRIR $8-13 \mu \mathrm{m}$ ) radiation. The second sensor is for very high resolution visual data (VHR) and very high resolution infrared data (WHR), visual and infrared sensors with the same wavelength bands as the high resolution sensor (HR). The spatial resolution of these sensors is a function of geomety. When specifying resolution, reference is made to the maximum spatial resolution at satellite subpoint, 2 nautical miles for the HR sensor and $1 / 3 \mathrm{n}$.mi. for the VHR-WHR sensor. Spatial resolution is however a function of distance from satellite subpoint and the resolutions degrade laterally to the extremities of each sweep or scan line to $14 \mathrm{n}$. mi . for HR-HRIR and $2 \mathrm{n}$. mi . for VHR-WHR. The sensors produce an analog signal proportional to the amount of incoming radiation. The analog signal is processed in two modes, it is digitized and transmitted in real time to remote sites, and it is tape recorded in analog form for later transmission to readout stations in the U.S.

The visual range sensors have sensor responses approaching zero at $0.4 \mu \mathrm{m}$ and again at $1.1 \mu \mathrm{m}$, with the peak of sensitivity at $0.8 \mu \mathrm{m}$. The half-power points are at approximately 0.57 and $0.97 \mu \mathrm{m}$. Since the strictly visual range is from 0.4 to $0.7 \mu \mathrm{m}$, a large part of what the visual sensors defect is a reflection of near infrared energy. The sensor measures the total radiation received in the full spectral range, and effectively integrates the sensorresponse equation. The analog output (video) signal is proportional to the area under the sensor-response curve. The brightness level of this video data is thus proportional to the total radiation in the range received while the amount of radiation at any given wavelength may vary. The spectral response beyond the $0.7 \mu \mathrm{m}$ point is useful in enhancing the contrast between vegetation and water, but some phenomena might become visible in the imagery that would be invisible to the unaided eye.

The infrared sensors use the $8-13 \mu \mathrm{m}$ atmospheric "window", which is relatively transparent to emitted radiation in this spectral range. This is an "imperfect window" however, with data contaminated by normal atmospheric constituents: namely ozone, carbon dioxide, water vapor, and aerosols. Of these contaminants, ozone and water vapor are most important. This contamination causes a variable amount of the radiation emitted from the sea surface to be absorbed and scattered. Natural variations in the amount of ozone and its distribution in the troposhere add only very small uncertainty to the infrared data. Water vapor has the most serious effect on the accuracy of sea surface temperatures from the infrared sensors. Nowhere in the $8-13 \mu \mathrm{m}$ range is the atmosphere completely transparent to infrared radiation, but water vapor absorption is least from $9.5-10.5 \mu \mathrm{m}$ increasing away from this narrow band.

The data from the HRIR sensors have been found to be a useful indicator of variations in sea surface temperatures, and thus an important source of coastal oceanographic data. The HRIR data, properly displayed provides a chart of sea surface temperature variations, 
mapped on a tranverse mercator projection. The data may be displayed at the largest scale of 1:7,500,000 along a swath of $1560 \mathrm{n}$. mi. astride the trace of the satellite subpoint. The infrared data from the HRIR sensor contains internal calibration values using deep space as the 0 level of power and a temperature-controlled sensor housing monitored by thermistors calibrated to within $0.2^{\circ} \mathrm{C}$ as a calibration source. The noise equivalent temperature difference is less than $1^{\circ} \mathrm{C} r . m . s$. over the full temperature range. The original analog signal covers the range of effective radiation temperatures from $210^{\circ}-310^{\circ} \mathrm{K}$. Within this range the global sea surface emits radiation in only the $273^{\circ} \mathrm{K}\left(0^{\circ} \mathrm{C}\right)$ to $303^{\circ} \mathrm{K}$ $\left(30^{\circ} \mathrm{C}\right)$ portion and in any particular geographic region in only a fraction of that range. The HRIR data can be displayed as imagery with 16 gray shace levels, each representing a temperature interval of $1.6^{\circ} \mathrm{C}$. In this way the sea surface emittance is mapped as a series of gray shades on $9^{\prime \prime}$ photographic film (figs. $5-10$ ), with a $1.6^{\circ} \mathrm{C}$ temperature resolution. The sensor records the amount of radiation being emitted by the sea surface minus atmospheric attenuation caused chiefly water vapor. The water vapor of the entire atmospheric column absorbs the sea surface radiation and reradiates at a lower temperature (assuming bulk of water vapor is colder than sea surface).

The sea surface temperatures detected by this sensor are from the top most radiating layer of the sea surface of less than $0.1 \mathrm{~mm}$ in thickness (Clark, 1967). Sea surface effects and the temperature gradient in the upper few millimeters of the sea may significantly influence the detected temperatures in comparison with temperatures measured using conventional surface measurement methods. Clark reports that vertical temperature drops of from $0.5^{\circ} \mathrm{C}$ to $1.0^{\circ} \mathrm{C}$ across a few millimeters of water are not uncommon and that behind a weather front the drop may be as large as $10^{\circ} \mathrm{C}$. However, infrared "skin temperatures" versus those obtained from the 3 meter depth ships hull mounted sensor during an experiment in Oct-Nov 1972, resulted in a mean temperature difference of only $.31^{\circ} \mathrm{C}$ in a sea state 2 (Beaufort scale) conditions. Slicks, sea state, foam, and spray also reduce infrared emittance with respect to the representative sea surface temperature. However, the most serious errors are introduced by clouds, smaller than the resolution of the sensors, which contaminate the data but go undefected. Then, surface observations or higher resolution remote sensing observations are necessary. Experiments comparing infrared effective radiation temperatures with actual sea surface temperatures of the DAPP system under clear sky conditions have shown differences ranging from $0-12^{\circ} \mathrm{C}$, cooler than the surface measurements. The errors were seen to be dependent on both the atmospheric conditions and path length of the observation through the atmosphere (angular displacement of the resolution element from the satellite subpoint). It is useful to observe that the spatial and thermal resolution of the DAPP system in effect provides a "low pass filter" on sea surface emittance. The scan spot values are effectively running average values of a small area 2-14 n.mi. in diameter, digitized into $1.6^{\circ} \mathrm{C}$ temperature ranges. This is a very coarse thermal resolution with respect to sensor sensitivity and calibration. The data provide a synoptic field of sea surface temperature values for direct incorporation into oceanographic operations, within minutes of the satellite overpass. The complicating factors affecting absolute values and geographic gridding must be rigorously considered when machine processing digital values at higher resolutions. Studies of the digital infrared data subjected to computer enhancement and gridding will be published at a later date. 
The principle use of the video data is for geographic gridding of images and identification of cloud-free areas. The coastal oceanographic use of video products is discussed in detail in section III of this report. Only the VHR (1/3 n.mi. resolution video) was used in this study, and it is available only for daytime, ascending node passes. During nightime passes, the high sensitivity HR video data can be used for accurate gridding in clear sky conditions, as city lights show up on the dark side of the earth.

The problems and process of gridding the data are described in the USAF DAPP Users Manual. The film product is essentially a strip chart with the image of the curved earth surface projected on a plane film surface. The display equipment rectifies the data (reducing the cylindrical distortion of foreshortening at the edges) and compensates for deviations of the spacecraft from normal attitude and altitude. Manual gridding according to instruction in the users manual, can locate land or oceanic features to within about $3 \mathrm{n}$.mi . along track and about $1.5 \mathrm{n}$. mi. across track near the data subpoint. Near the edge of the data the error may increase to as much as $13 \mathrm{n}$. mi. along track and $8 \mathrm{n}$. mi. across track due to space craft yaw errors that cannot be compensated for in the display. The accuracy can be improved by adjusting the grid using geographical references and clear sky VHR daia. However, when there is a yaw error the grid will be accurate at the geographic reference points, and error will increase away from those points.

In the following section procedures for coastal oceanographic use of the DAPP system will be specified with examples of the products. Normal meteorological display modes do not reveal the oceanographic information content of the DAPP system data.

\section{PROCEDURES FOR COASTAL OCEANOGRAPHIC USE}

\section{Display of Video Data (VHR)}

The optimum display mode of the visual range data for oceanographic use is low-level enhancement and expansion of the image. Enhancement of low-level reflections brings out the maximum detail in the oceanic and terrestrial regions free of clouds. Expansion of the film products to a scale of $1: 7,500,000$ versus the normal $1: 15,000,000$ provides fullest use of resolution capabilities and the most accurate manual gridding. In this way the best presentations of intricate coastline features in video and complex ocean thermal patterns in infrared data are obtained. The uses of the video image are as follows:

- determination of cloud free areas for the most reliable HRIR sea surface temperature data,

- detection of patterns of reflected light from the oceanic areas,

- location of land mass features of the region for manual gridding and geographic reference,

- location of satellite subpoint track with respect to the area of interest.

The patterns of reflected light from oceanic regions have not been subject to field checks or positively identified. Changes in video gain along the track during a pass, significantly alter the amount of visual range reflection apparent from the sea surface. 
Gain change may suddenly cause an apparent sea surface structure to be lost or acquired in the image (fig. 2, note 1, line A). Tentatively, the reflection patterns attributable to the oceanic effects are as follows:

1. Reflections from the Sea Floor in Shallow Water Areas - Many images of the Yellow Sea suggest that the video data contain reflections from the bottom in areas with depths as great as 10 fathoms. Persistence of position and form over many months suggest that these features may be sea floor reflections, rather than suspended sediments moving over the shallows (fig. 2), but this is unverified.

2. Reflection from Turbid Surface Waters in Deep Water Areas - Aircraft underflights during the experiments off South Korea have shown turbid plumes and extensive coastal turbidity along the southeast coast of the peninsula (see fig. 3 ). In this region the water depths increase rapidly and reflections in DAPP data are obtained from the surface waters in areas of 600 foot water depths.

3. Reflection from Areas of High Sea State and Extensive Whitecapping of Waves The development of substantial amounts of white foam by strong winds and high seas, when combined with cloud free skies may produce more reflective areas on the sea surface. Very sharp boundaries have been seen by aircraft between whitecapped and whitecap free areas associated with oceanic thermal fronts. Figure 3 appears to have a series of patterns of sea state differences, but no field verifications have been accomplished to date.

\section{Display of Infrared Sea Surface Temperature Data (HRIR)}

The temperature range of -2 to $30^{\circ} \mathrm{C}$ covers more than 90 percent of the surface temperatures around the globe (Montgomery, 1958). This $32^{\circ} \mathrm{C}$ range is slightly less than one third of the full range, $100^{\circ} \mathrm{K}$, of the system. For any particular oceanic region (i.e. linear distances of tens of miles) the temperature range is much less, more in the order of a few degrees, with some regions up to ten degrees. As a result of experiments in the strong gradient areas off the Korean Peninsula, the following procedure was established for obtaining synoptic sea surface thermal structure from the remote-site readout vans:

1. Infrared Data Display Brilliance Inversion Mode (MI 1) - Use the 16 gray shades for charting sea surface temperature patterns (fig. 12).

2. Temperature Range Expansion ( $X_{4}$ setting) - The system has a calibrated temperature sensitivity range of $210-310^{\circ} \mathrm{K}$. There are three temperature expansion settings, $X_{1}, X_{2}$, and $X_{4}$, which vary the range of temperatures over which the 16 gray shades are spread. $X_{1}$ covers the entire $100^{\circ} \mathrm{K}, X_{2}$ can cover any $50^{\circ} \mathrm{K}$ span, and $\mathrm{X}_{4}$ any $25^{\circ} \mathrm{K}$ span of temperatures (fig. 12).

3. Brilliance Inversion Base Temperature Setting - This value determines the warmest temperature included in the gray shade scale, of a particular display, and fixes the temperature range which the 16 gray shades will cover. By setting a base temperature of $298^{\circ} \mathrm{K}\left(0^{\circ} \mathrm{C}=273^{\circ} \mathrm{K}, 25^{\circ} \mathrm{C}=295^{\circ} \mathrm{K}\right)$ the $\mathrm{X}_{4}$ temperature range of $25^{\circ} \mathrm{C}$ is displayed in the range of $0-25^{\circ} \mathrm{C}$, the interval of most sea surface temperatures encountered (fig. 12). Slightly different settings of the base temperature may be required to produce the highest quality images under different oceanic and atmospheric conditions. By experimenting with several degree variations in base 
temperature setting, it is possible to maximize the contrast between land and sea and among the ocean thermal features.

4. Image Expansion - Data from each pass covers a region 1,560 nautical miles wide which can be displayed at two scales, 1:15,000,000 or 1:7,500,000. At normal scale the entire pass is displayed on 9" film at the scale of 1:7,500,000. However, magnification of expansion of the image is possible, allowing the observer to view half of the full swath of data expanded to fill the entire width of the 9" film at scale of $1: 7,500,000$. One can expand the center, left, or right halves at any image.

The display of a sea surface temperature gradient is illustrated schematically in figure 13. On the ordinate, is a plot of satellite temperature and gray shade scales, with the corresponding Celsius temperatures. The abscissa is distance in nautical miles from the Korean coast. The trace is actual sea surface temperature data measured by a ship's hull mounted thermometer 3 November, 1972. Shown at the top is the gray shade display of this temperature gradient in the same manner it would show on satellite imagery. The resultant image, a film product, is a chart (transverse mercator projection) of the sea surface thermal patterns represented by 16 gray shades. (Note - the great improvement for oceanographic use possible if a thermal resolution of $0.5^{\circ} \mathrm{C}$ were available vice the $1.6^{\circ} \mathrm{C}$ illustrated here).

Figure 5 is an example of these $\mathrm{Ml} 1$ and $\mathrm{X}_{4}$ data with $295^{\circ} \mathrm{K}$ as the base temperature. The film product was used directly as a negative to produce the figures. The black areas are colder than $270^{\circ} \mathrm{K}\left(0^{\circ} \mathrm{C}\right)$, the white areas are warmer than $295^{\circ} \mathrm{K}\left(25^{\circ} \mathrm{C}\right)$. The representation of warm regions as lighter shades is the convention used in this work. Clouds show up as black areas, and land masses show up as white during daytime passes and black during nightime passes*. This convention allows rapid reproduction of thermal imagery without production of a negative.

Specific recommendations for handling data acquisition at remote-site receivers are as follows:

1. Produce a VHR film product (for ascending nodes) or an HR film product (descending node pass) directly from the satellite and store the IR signal on tape.

2. During rewind of tape:

a. produce an $\mathrm{Ml} 1$ gray scale test pattern so that the 16 gray shades and the corresponding temperature intervals can be exactly identified on the HRIR product.

3. Produce the MII HRIR product from the tape recorded data.

The gridded visual data and the calibrated gray-scale wedge from the test pattern can then be used in interpretation of the HRIR data.

* These infrared images are thus tonally inverted from the original rear real-time products and the conventional meteorological displays. 
The procedures and images presented here are the results of experiments with remote site data in east Asia, principally the Yellow Sea, Sea of Japan, and the Sea of Okhotsk. There exist many advantages of this region for experiments of this nature. The Sea of Japan and Yellow Sea are marine basins of contrasting character. The Yellow Sea is a shallow basin (maximum depth $100 \mathrm{~m}$ ) of strong tidal current activity, major rivers and deltas, and much runoff containing a relatively high suspended sediment load (fig. 1). The Korean Strait (between Korea and Japan) is also of continental shelf depth, $203 \mathrm{~m}$. in the west channel and $108 \mathrm{~m}$ in the east channel with bottom dropping off steeply just north of the strait. The Sea of Japan is a deep basin $(3000 \mathrm{~m})$, having small tide ranges $(<15 \mathrm{~cm})$, no major rivers, and is surrounded by narrow continental shelves. The Sea of Okhotsk in winter has abundant sea ice, of which the VHR data provides excellent images (fig. 4).

Strong thermal gradients occur in the surface waters of the Sea of Japan (fig. 9). In the region off the east coast of Korea and in the Korean Strait (see Fig. 1) three and sometimes four water masses occur, depending on season (Gong, 1971). The surface temperature differences between them vary from $4-8^{\circ} \mathrm{C}$. The Tsushima Current, a branch of the Kuroshio (a western boundary current equivalent to the Gulf Stream), provides a "jet" of warm surface water through the Korean Strait into the Sea of Japan (Figs. 5, 6, and 9). The temperatures detected in this area by shipborne measurements ranged from $14-24^{\circ} \mathrm{C}$ (October, November 1972). The Tsushima Current waters here range between 20$24^{\circ} \mathrm{C}$, the Korean Coastal waters between $17-19^{\circ} \mathrm{C}$, and the upwelling waters between $14-16^{\circ}$. These bodies of water had strong thermal gradients separating them in order of $2.4^{\circ} \mathrm{C}$ per nautical mile (see figure 11 ). Because of these steep gradients, fronts, frontal waves, mesoscale cyclonic and anticyclonic eddies are sharply defined in this region by the gross $1.6^{\circ} \mathrm{C}$ temperature bands represented by each successive $\mathrm{Ml}_{1} \mathrm{X}_{4}$ gray shade. In the Yellow Sea the horizontal thermal gradients are much weaker (figs. 6 and 7 ), due to the smaller inflow of warm waters and vertical mixing accomplished by the strong tidal currents.

The HRIR data actually mapped the surface extent of the ocean currents and fronts, showing them outlined by the gray-shade patterns (see Tsushima Current, figure 5, 6, Yellow Sea Warm Current, figure 6, and Yellow Sea Cold Current, figure 7). The DAPP operators, with HRIR data on effective radiation temperatures of the sea can thus provide search and rescue units information on water temperatures and in the case of known ocean currents, probable direction of drift. During oceanographic operation NUGGET RANCH (10 October - 10 November 1972) the synoptic HRIR data were used to supplement direct sea surface temperature measurements, for decision making on spacing and positioning of ship tracks, to detect and position water masses, and to measure water mass boundary translocations, rather than to substitute for standard oceanographic methods.

The VHR data appear to show the ocean floor to depths of 10 fathoms (60 feet). If this suspicion is sustained by future field tests the DAPP system may have some use in detection and verification of ship reports of dangerous shoal waters in poorly surveyed oceanic areas*. The detection of sea ice in the Sea of Okhotsk is illustrated in Figure 4.

\footnotetext{
* However except for high repetition rate this function can better be performed by higher resolution systems such as ERTS or various photographic systems.
} 
Time-lapse imaging of ice (as well as surface isotherms) can detect motions and trajectories valuable for safe ship navigation and measurements of oceanic circulation.

In summary, although designed for meteorological applications, the DAPP system has inherent oceanographic capabilities, which will provide an important foundation of information for development of a practical oceanographic satellite, and baseline synoptic data on waters of the globe. This effort was designed to test the value to coastal oceanography of both the DAPP system and this entire approach. In the end the DAPP system was actually used to steer an entire surface-truth operation. It gave a quick synoptic overview, the perfect perspective for operational decision making. This is a most useful development in view of today's funding situation, where research vessels are being withdrawn from service. It also coincides with a time when the coastal oceanographic community is concentrating on multiship synoptic studies and beginning to fully appreciate the mesoscale turbulent structure of coastal regions as well as the open ocean. The satellite remote sensing approach is the means to make optimum use of limited ship time, to conduct "smart ship" operations in the sense that the investigator has time-lapse near real-time synoptic data to direct his sampling program. This, perhaps will be one of the most far reaching concepts derived from the work.

\section{ACKNOWLEDGEMENTS}

This study was funded by the Office of Naval Research, Geography Programs (Remote Sensing) Code 414, under contract NR 387-062, as part of the Coastal Advection Research Project at the Naval Oceanographic Office. Special appreciation is extended to Dr. James S. Bailey of ONR, for initial access to the system and helpful constructive criticisms during the progress of the study. Appreciation is extended to CDR K. Ruggles and LCDR W. Mitchell of Detachment FAMOS, Naval Weapons Engineering Support Activity (197172) NAVAIR Systems Command for introduction and initial guidance on the DAPP. The author gratefully acknowledges the help and support of Naval Space Systems Activity, located at Space and Missile Systems Organization, Los Angeles, for guidance, special clearances, and essential procurements of system related materials. Critical to the success of this project has been the outstanding cooperation and highest standards of professionalism displayed throughout this effort by U.S. Air Force Personnel of the 20th Weather Squadron, SAMSO, and the Air Force Global Weather Central, Offutt, Nebraska. 


\section{REFERENCES}

Blanton, Jackson, 1971, Exchange of Gulf Stream Water with North Carolina Shelf Water in Onslow Bay during stratified conditions, Deep Sea Research, Vol. 18, pp. 167-178.

Clark, H.L. 1967, Some Problems Associated with Airborne Radiometry of the Sea, Applied Optics, Vol 6, No. 12, pp. 2151-2157.

Defant, A. 1961. Physical Oceanography, Vol 1, 729 pp, Pergamon Press, London.

Gong, Yeong, 1971. A Study on the South Korean Coastal Front, The Journal of the Oceanological Society of Korea, Vol. 6, No. 1, p. 25-36.

Griffiths, Raymond C. 1965. A Study of Ocean Fronts off Cape San Lucas, Lower California, U.S. Fish and Wildlife Service, Special Scientific Report, Fisheries No. 499, Wash. D.C. $53 \mathrm{pp}$.

Laevastu, T, and E.C. Lafond, 1970, Oceanic Fronts and their Seasonal Positions on the Surface. Naval Undersea Research and Development Center, NUC TP-204, San Diego, California, $16 \mathrm{pp}$.

Montgomery, R.B. 1958, Water Characteristics of Atlantic Ocean and of World Ocean, Deep-Sea Research, Vol 5, pp。134-148.

Sverdrup, H.U., M.W. Johnson, and R.H. Fleming, 1942, The Oceans, Their Physics, Chemistry, and General Biology, Prentice-Hall, Inc. Englewood Cliffs, N.J. 1060 p.

Uda, M. 1938. Research on "Siome" or current rip in the seas and oceans. Geophys. Mag. 307-372.

U.S. Air Force, 1971, Data Acquisition and Processing Program (DAPP) (U) Users Guide, Vol 1, Classified publication with unclassified sections. 


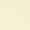




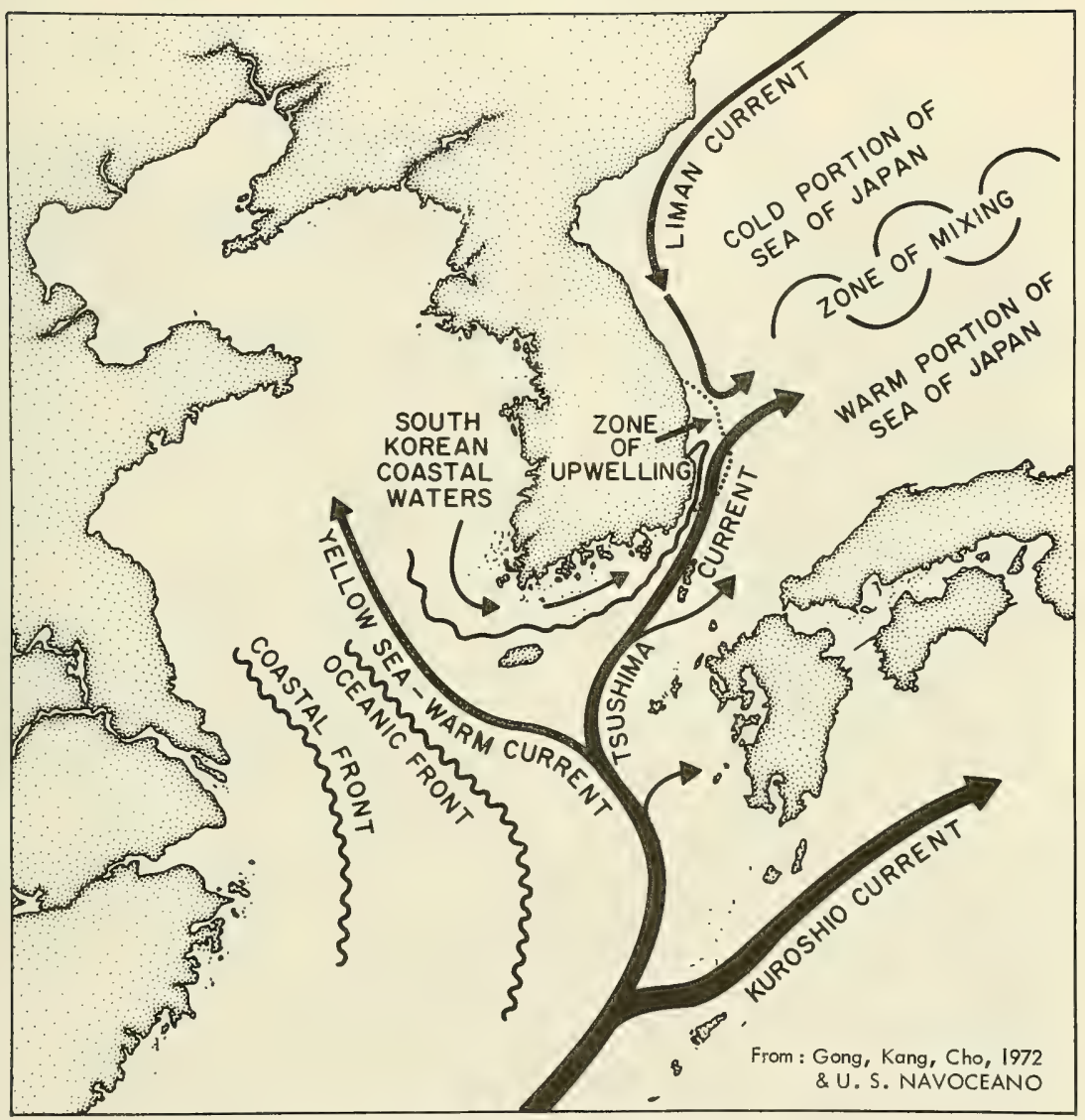

PHYSICAL OCEANOGRAPHIC FEATURES

FIGURE 1 . 
Figure 2 - VHR data, Yellow Sea, Korean Peninsula, and western Sea of Japan. Ascending node, low entance, expand center, of 4527/599, at $1504 \mathrm{Z}$ on 25 November 1971, 1/3 n.mi. resolution video data.

NOTE: (1) gain change at Line (A) and variation in apparent intensity of reflections in vicinity of Yangtse River Delta.

(2) Reflection of light from shallow water regions just seaward of the coastlines (B). 


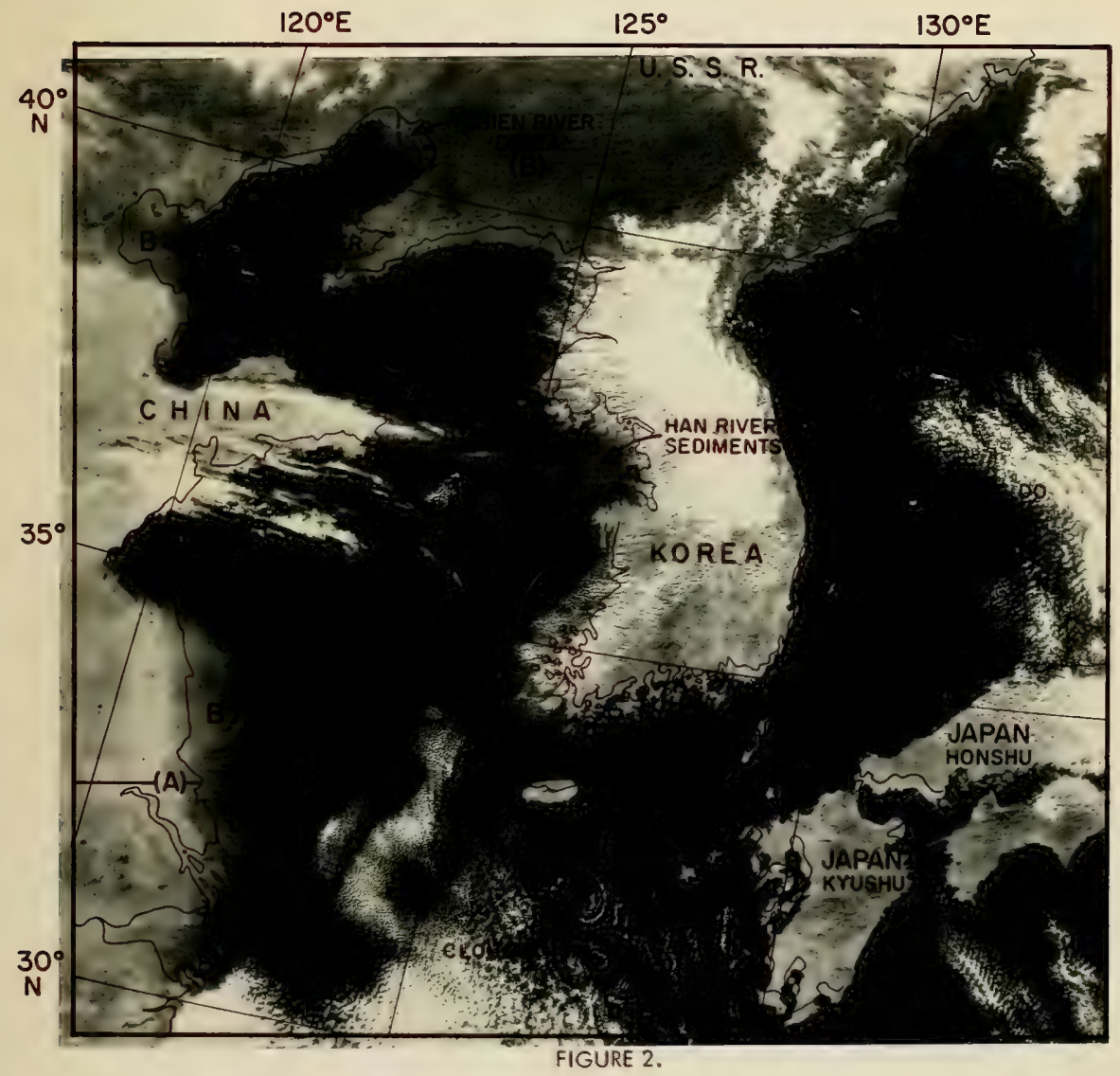


Figure 2 - VHR data, Yellow Sea, Korean Peninsula, and western Sea of Japan. Ascending node, low enhance, expand center, of 4527/599, at 1504Z on 25 November 1971, 1/3 n.mi. resolution video data.

NOTE: (1) gain change at Line (A) and variation in apparent intensity of reflections in vicinity of Yangtse River Delta.

(2) Reflection of light from shallow water regions just seaward of the coastlines (B).

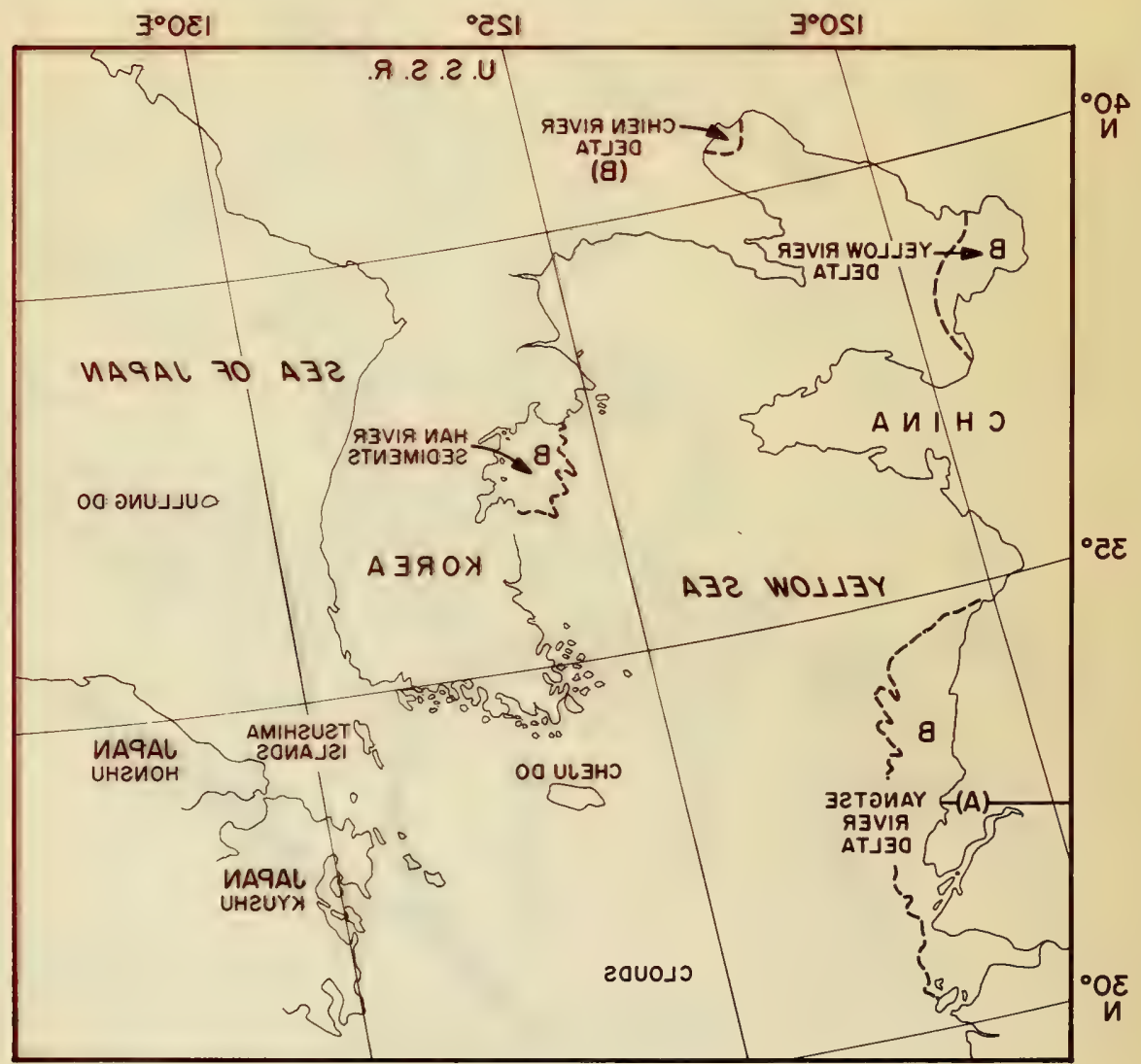

.S $\exists$ ЯบอІ7 


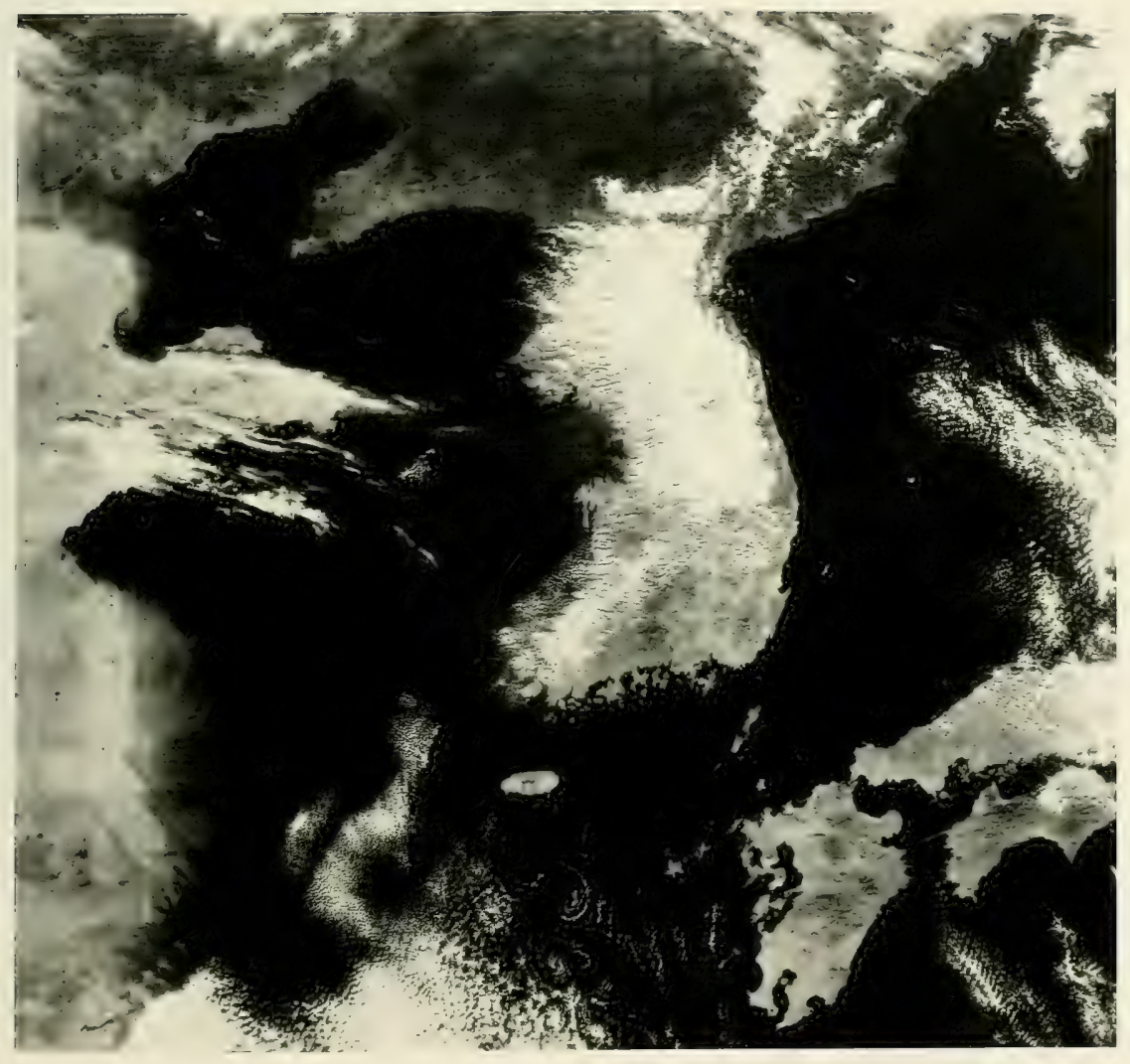




Figure 3 - VHR data, eastern Yellow Sea, Korean Paninsula, southwestern Sea of Japan. Ascending node 0319Z, 28 April 1972, 5528/492, low enhance, expand center, I/3 n.mi. resolution video data.

NOTE: A. Gray shades outlining coastal turbidity.

B. Gray shades outlining reflection differences. The wind direction was from SW, $11 \mathrm{kts}$.

C. Lee shadow of Japanese Islands. 


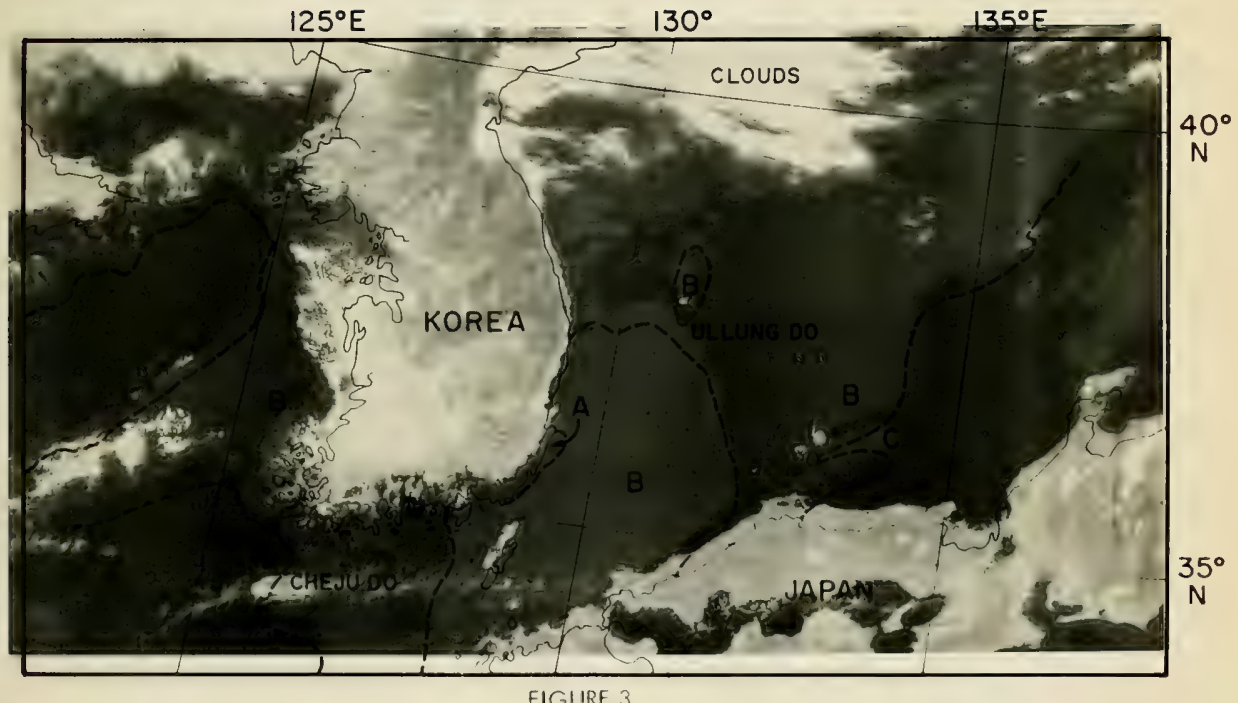

FIGURE 3 
Figure 3 - VHR data, eastern Yellow Sea, Korean Paninsula, southwestern Sea of Japan. Ascending node 0319Z, 28 April 1972, 5528/492, low enhance, expand center, 1/3 n.mi. resolution video data.

NOTE: A. Gray shades outlining coastal turbidity.

B. Gray shades outlining reflection differences. The wind direction was from SW, 11 kts.

C. Lee shadow of Japanese Islands.

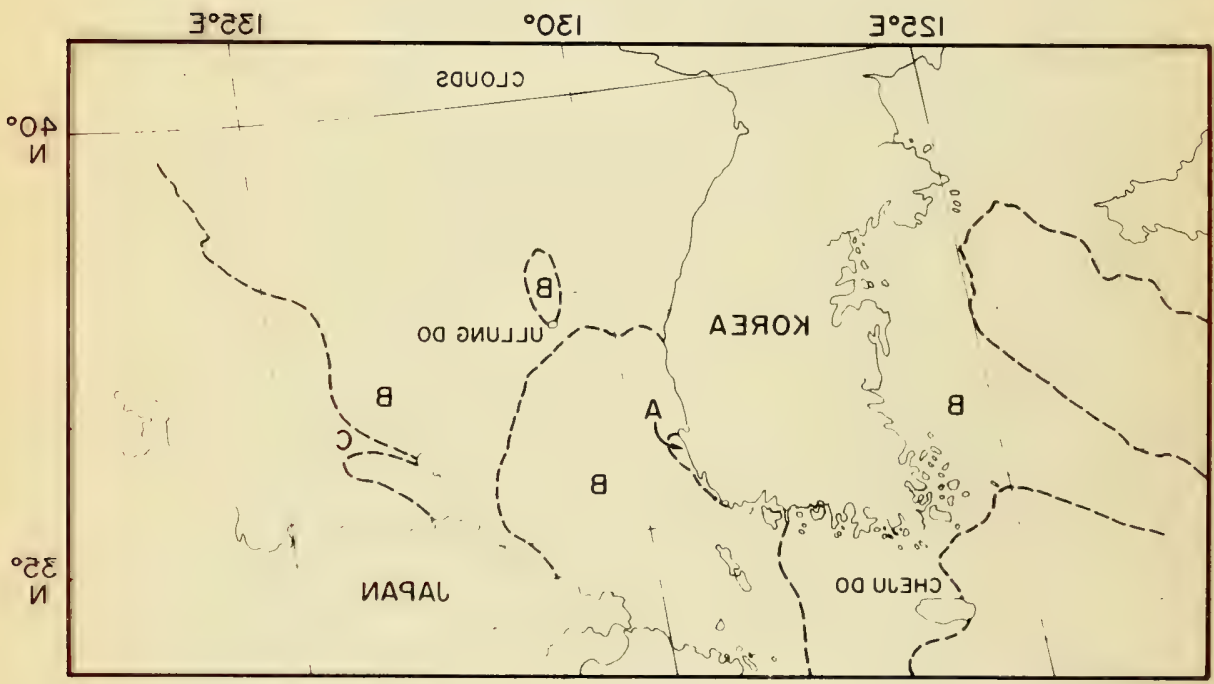

ย 


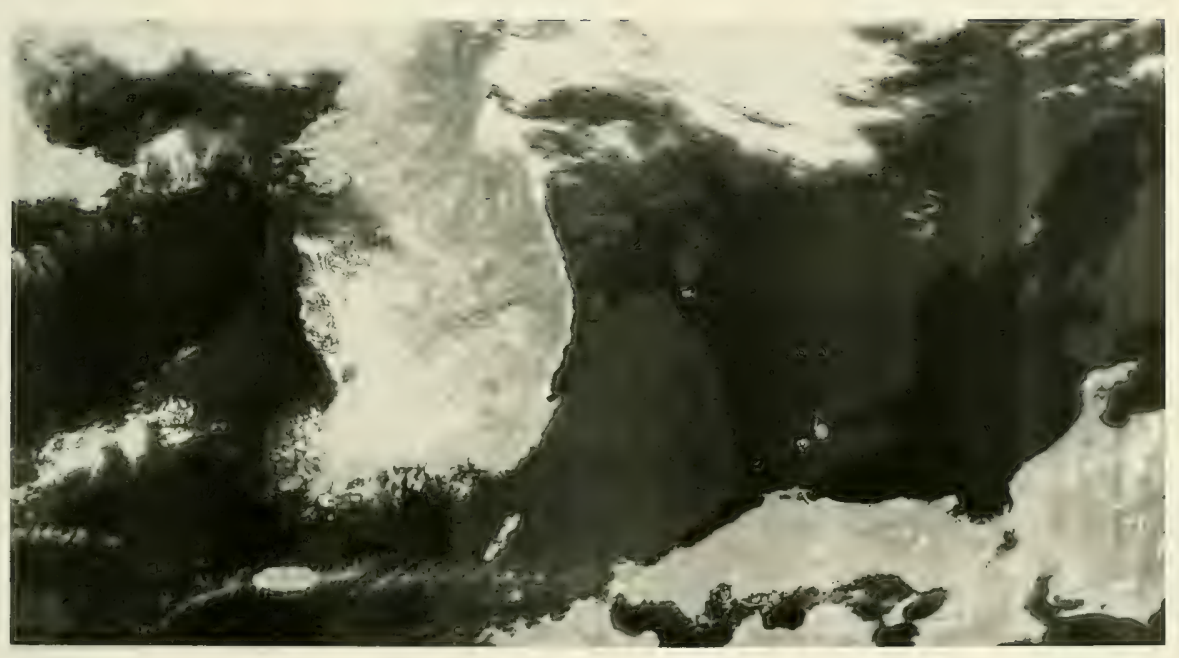



, 
Figure 4 - VHR data, northeast Sea of Japan, Soviet Coast, Sakhalin, and the western portion of the Sea of Okhotsk. Ascending node 0147Z, 13 April 1972, 5528/279, low enhance, expand center, $1 / 3 \mathrm{n}$. mi . resolution visual range data.

NOTE: 1. The "granular" structure and fracturing of the sea ice in the Sea of Okhotsk (east and north of Sakhalin). All of the drift ice seen is probably $50-90 \mathrm{~cm}$ thick and the variation in shading is due to variation in ice concentrations (from 3 to 10 tenths) north of the ice edge.

2. West of Sakhalin, off the mouth of the Amur River, the landfast ice is mostly white with the dark band against the coastlines representing snow water on the ice and surface puddling of the ice itself.

3. The surface water flow patterns outlined by drift ice on the sea surface northeast of Hokkaido.

4. In the Sea of Okhotsk the wind drift as a result of the Siberian High Pressure System moves the ice southeastward creating the shore polynyas noted and causing the ice strings along the eastern ice edge. 


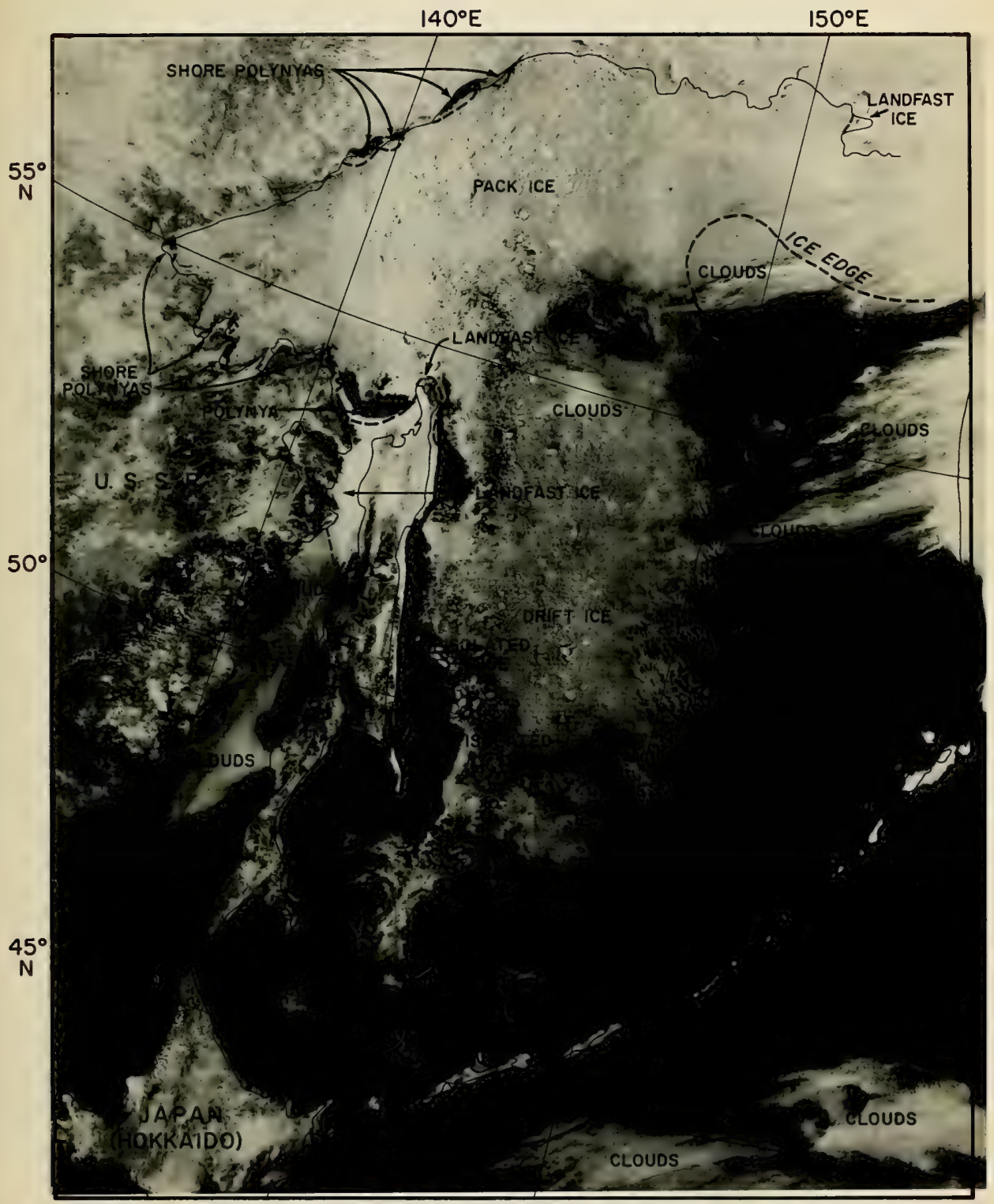

FIGURE 4. 
Figure 4 of the Se

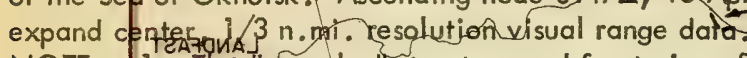

$3{ }^{\circ} \mathrm{g}+1$ I Sakbalin, and the western portion NOTE:

Doe egranular"structure and fracturing of thesea $/ c=$ in the Sea of Okhotsk (east and north of Sakhalin). All of the drift iceseen is probably $50-90 \mathrm{~cm}$ thick and the variation in shading is due to yariation in ice concentrations (from 3 to 10 tenths) north of the ice edge.

2. West of Sakkglinn, off the mouth of the Amur River, the landfast ice is mostly white wis? the dark band against the coastlines representing snow watengon the ice alo 'surface pudding of the ice itself.

3. Theusurface water flow patterns outlined by drift ice on the sea surface northeast of Hokkaido.

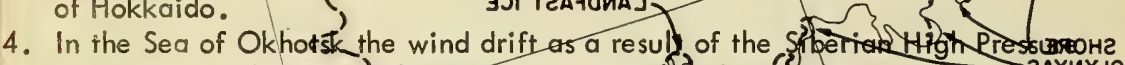

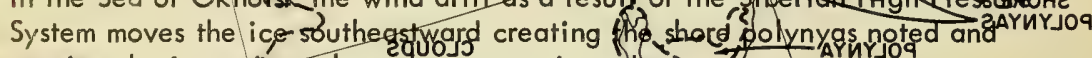
zorosing the ice strings along the eastern ice ebdye :-
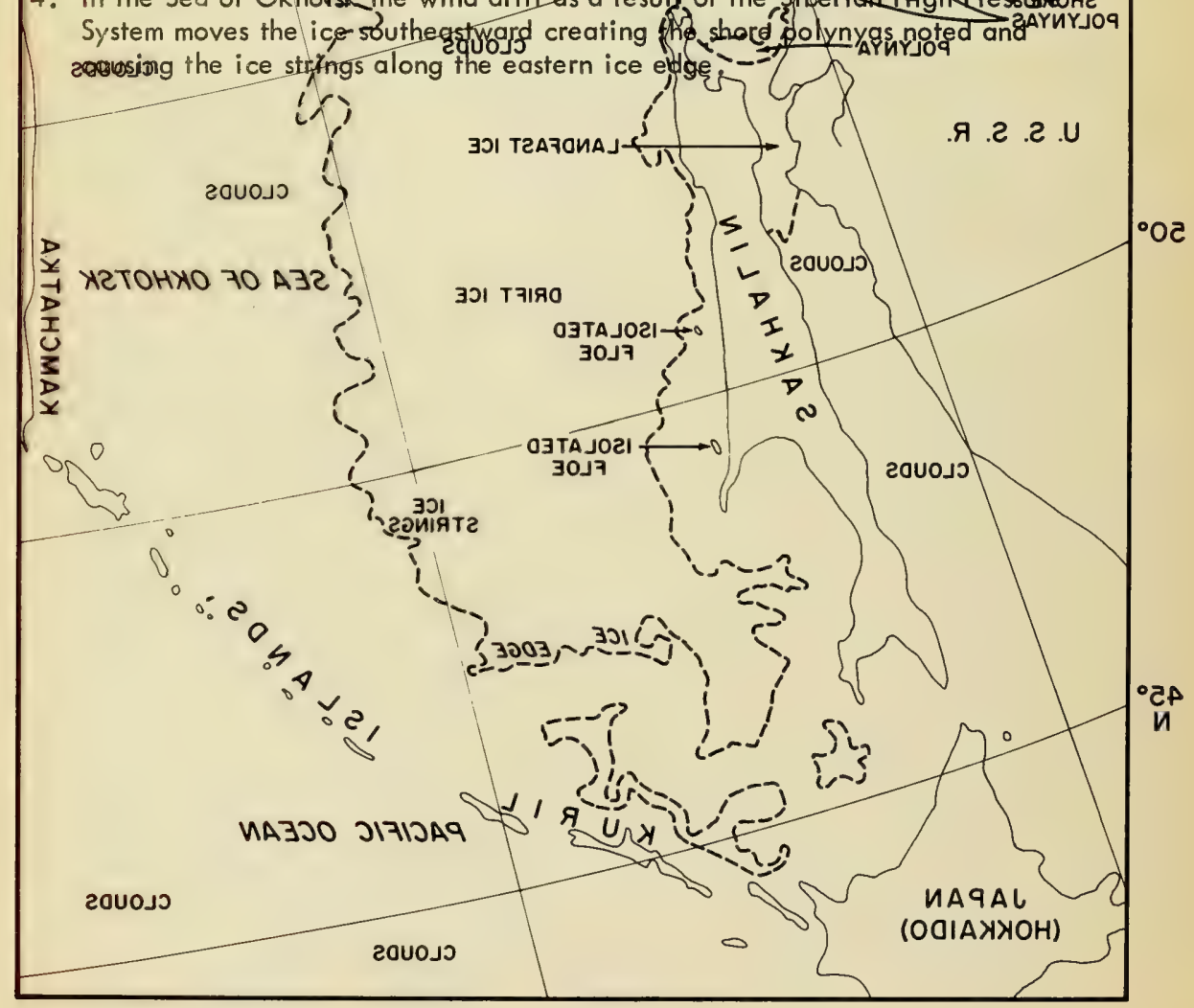


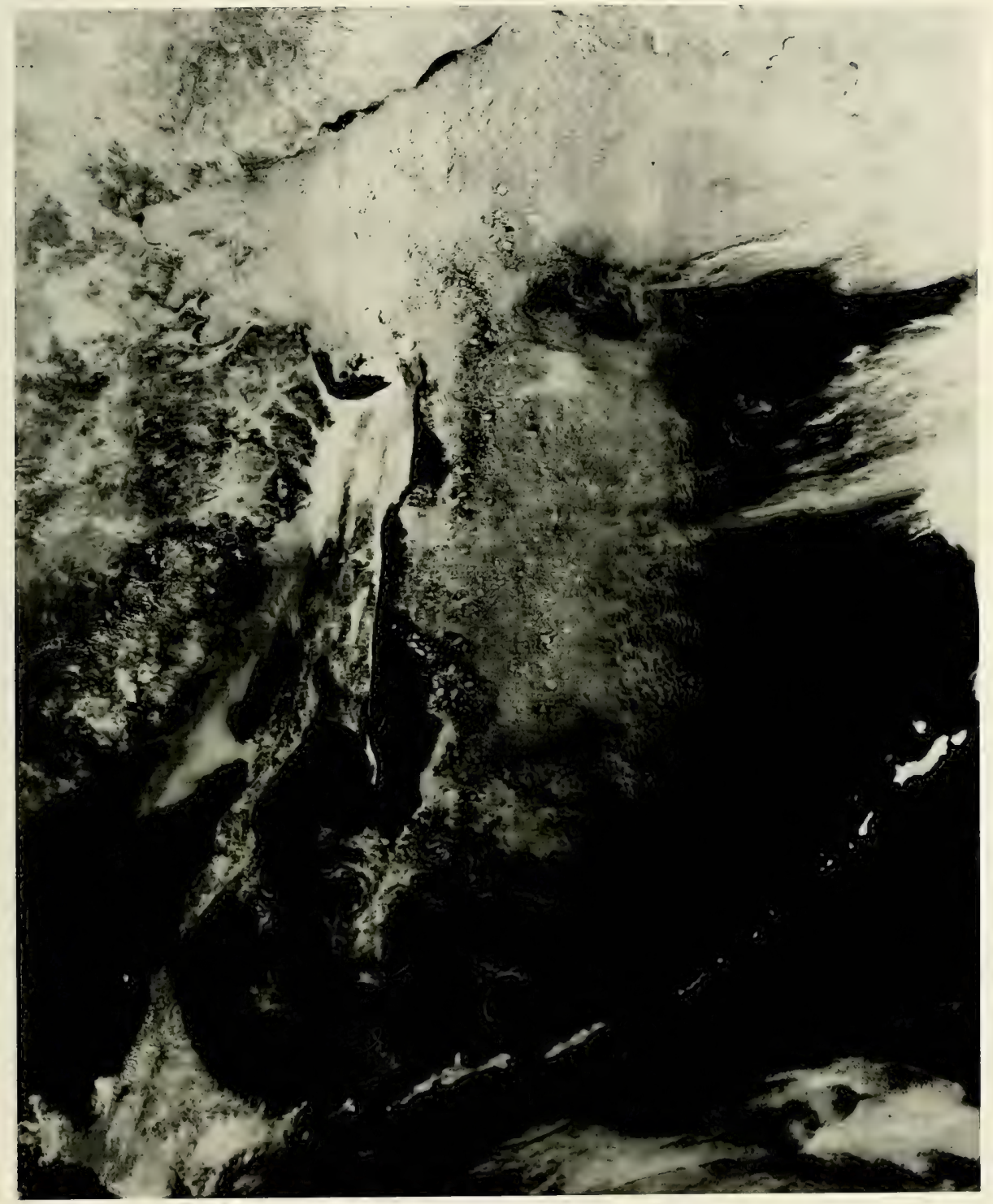



Figure 5 - HRIR data, eastern Yellow Sea, Korean Peninsula, and western Sea of Japan. Ascending node, 0319Z, 28 April 1972, 5528/492, expand center 2 n.mi. resolution infrared data, $\mathrm{MI}_{1}, \mathrm{X}_{4}, 290^{\circ} \mathrm{K}$. Contact print using film display of data as a negative. NOTE: 1. Clouds displayed as black as a negative.

2. Korean Peninsula and other land masses sun warned to effective radiating temperatures greater than the sea.

3. Thermal scar of Tsushima Warm Current east and west boundaries and trajectory of warm waters in the Sea of Japan. 


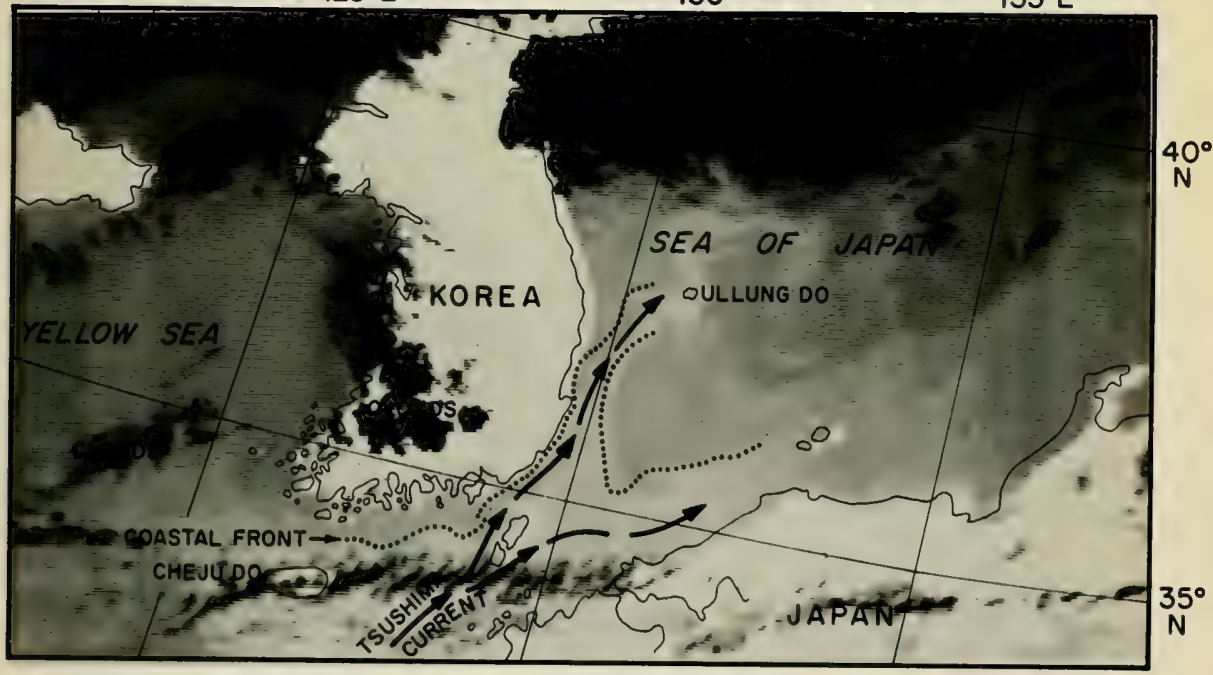

FIGURE 5. 
Figure 5 - HRIR data, eastern Yellow Sea, Korean Peninsula, and western Sea of Japan. Ascending node, 0319Z, 28 April 1972, 5528/492, expand center 2 n.mi. resolution infrared data, $\mathrm{Ml}_{1}, \mathrm{X}_{4}, 290^{\circ} \mathrm{K}$. Contact print using film display of data as a negative. NOTE: 1. Clouds displayed as black as a negative.

2. Korean Peninsula and other land masses sun warned to effective radiating temperatures greater than the sea.

3. Thermal scar of Tsushima Warm Current east and west boundaries and trajectory of warm waters in the Sea of Japan.

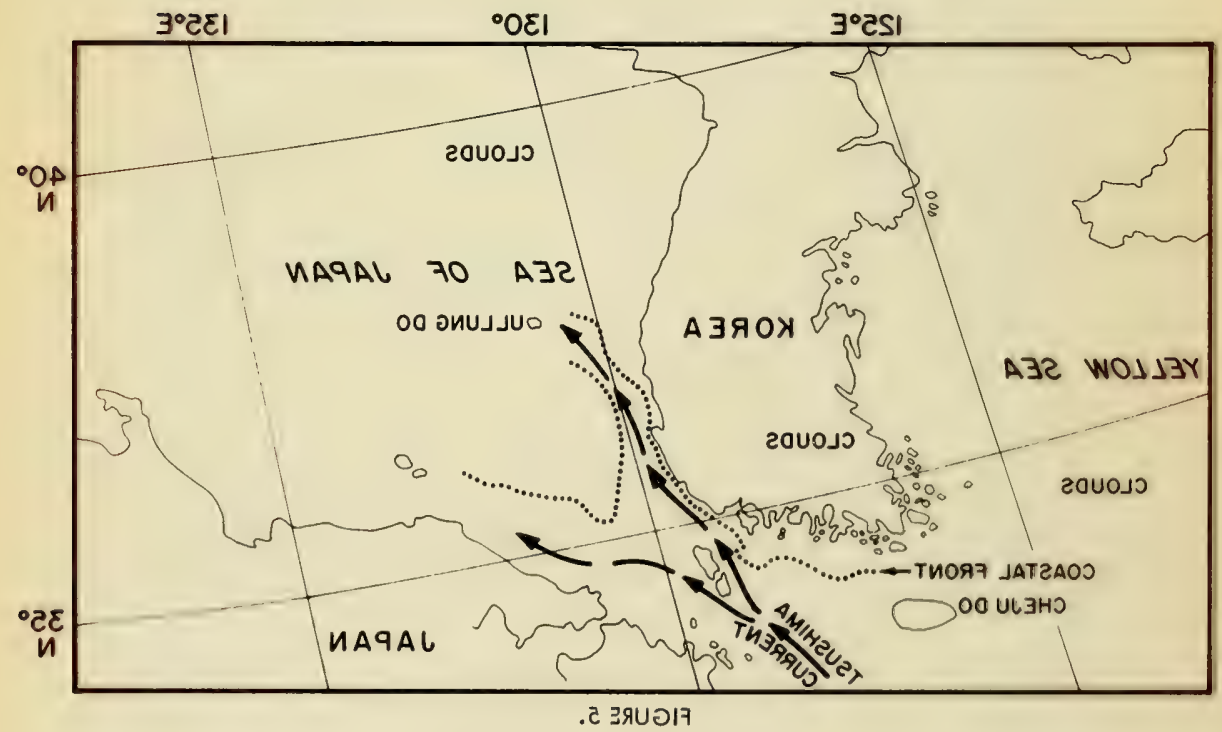




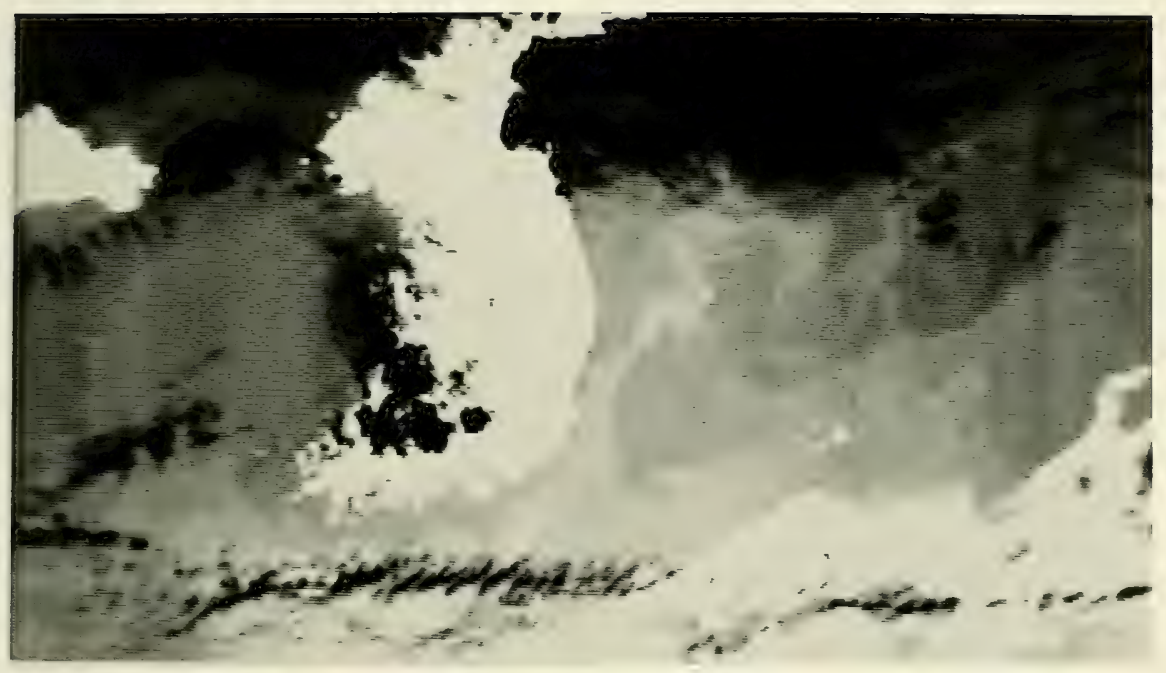



. 
Figure 6 - HRIR data, Yellow Sea, Korean Peninsula, western Sea of Japan. Ascending node, 0223Z, 10 April 1972, 4527/2532, expand right. MI1, $\mathrm{X}_{4}, 291^{\circ} \mathrm{K}, 2 \mathrm{n}$.mi . resolution infrared data. Contact print using film product directly as a negative. Clouds displayed black, land masses displayed white.

NOTE: 1. Warm currents in the Sea of Japan and Yellow Sea

2. Strong thermal gradients in the Sea of Japan and weak gradients in the Yellow Sea (a region of shallow water and strong tidal mixing). 


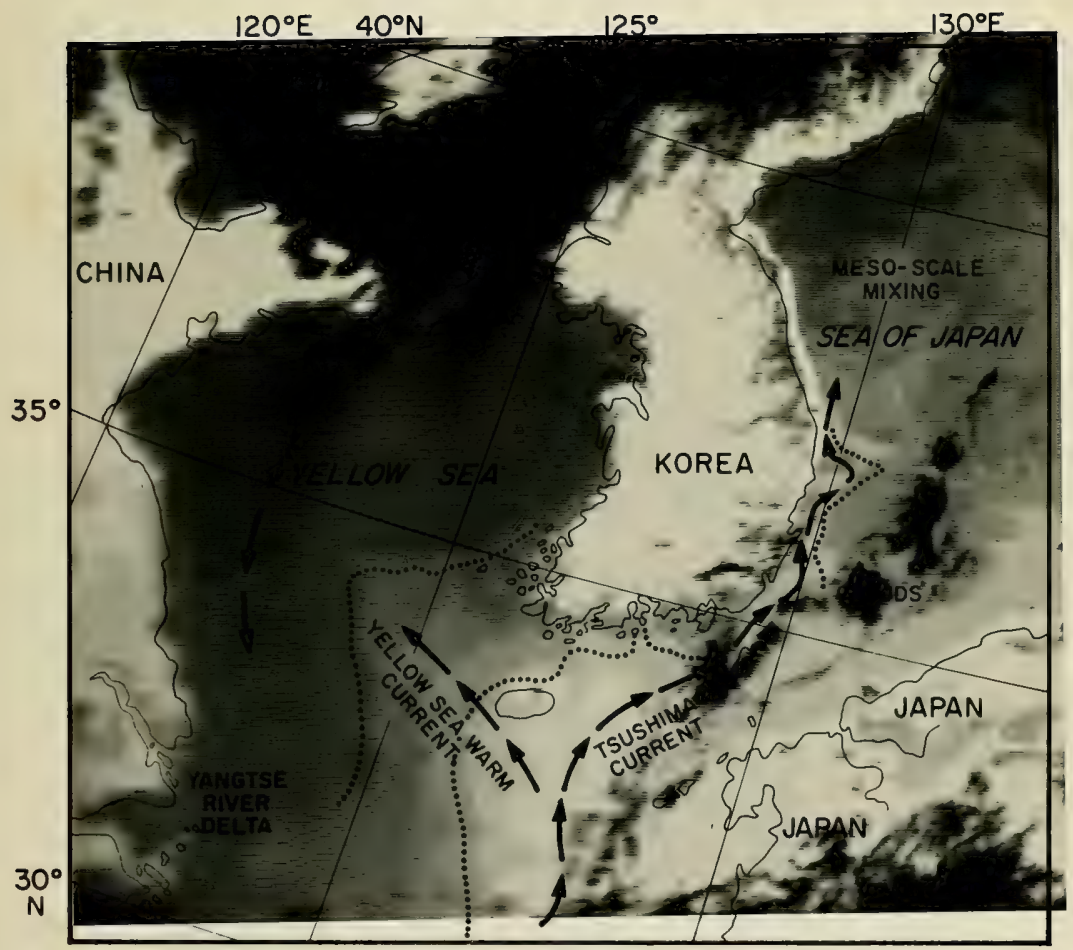

FIGURE 6. 
Figure 6 - HRIR data, Yellow Sea, Korean Peninsula, western Sea of Japan. Ascending node, 0223Z, 10 April 1972, 4527/2532, expand right. MI1, $\mathrm{X}_{4}, 291^{\circ} \mathrm{K}, 2 \mathrm{n}$.mi . resolution infrared data. Contact print using film product directly as a negative. Clouds displayed black, land masses displayed white.

NOTE: 1. Warm currents in the Sea of Japan and Yellow Sea

2. Strong thermal gradients in the Sea of Japan and weak gradients in the Yellow Sea (a region of shallow water and strong tidal mixing).

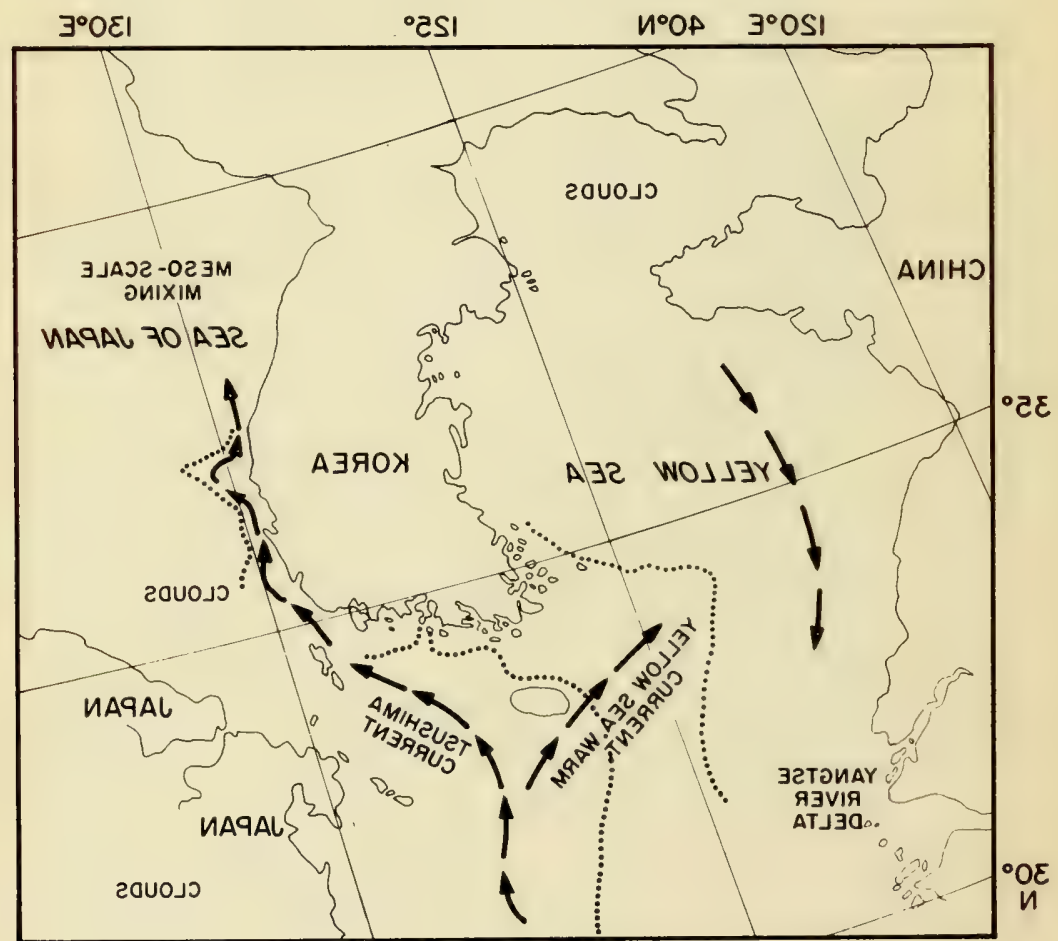

. 


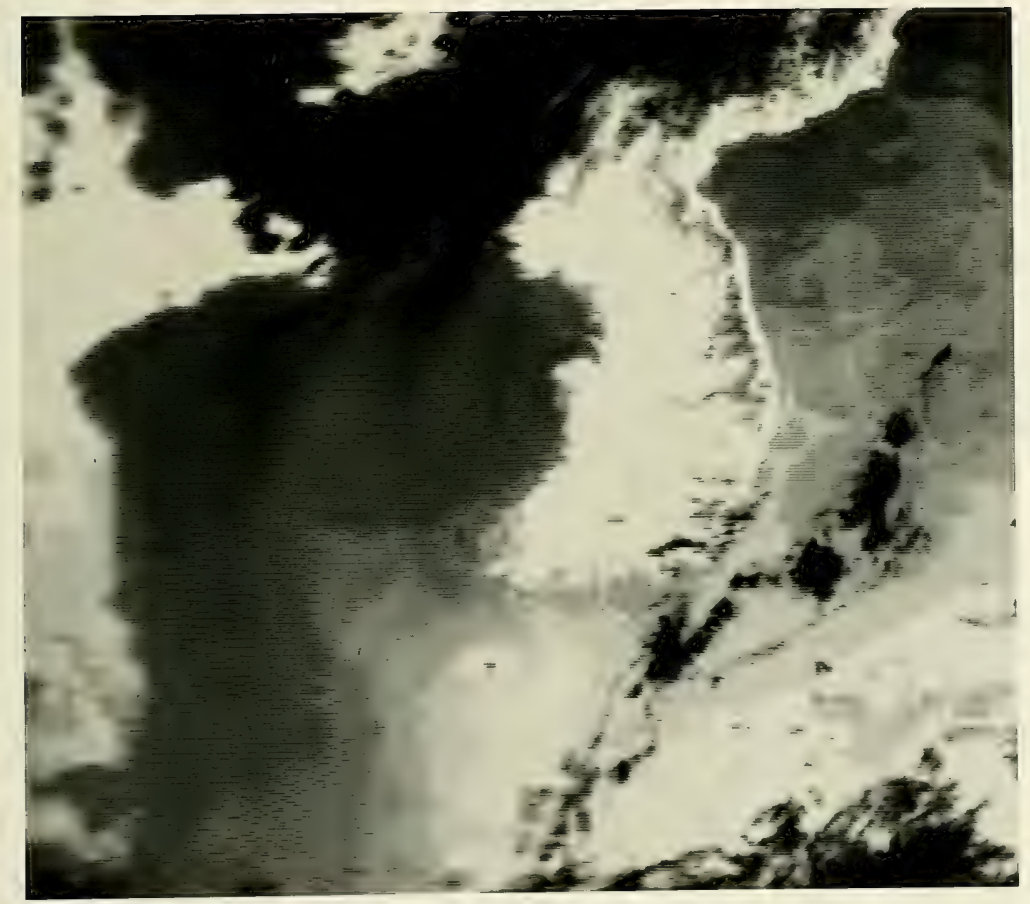




Figure 7 - HRIR dara, China Coastal Current in the Yellow Sea. Ascending node, 0309Z, 1 April 1972, 4527/2405, expand center, Ml I, $\mathrm{X}_{4}, 291^{\circ} \mathrm{K}, 2 \mathrm{n}$. mi. resolution infrared data.

NOTE: The China Coastal Current detected as a tongue of cold water extending from the Gulf of Po Hai south along the western side of the Yellow Sea. 


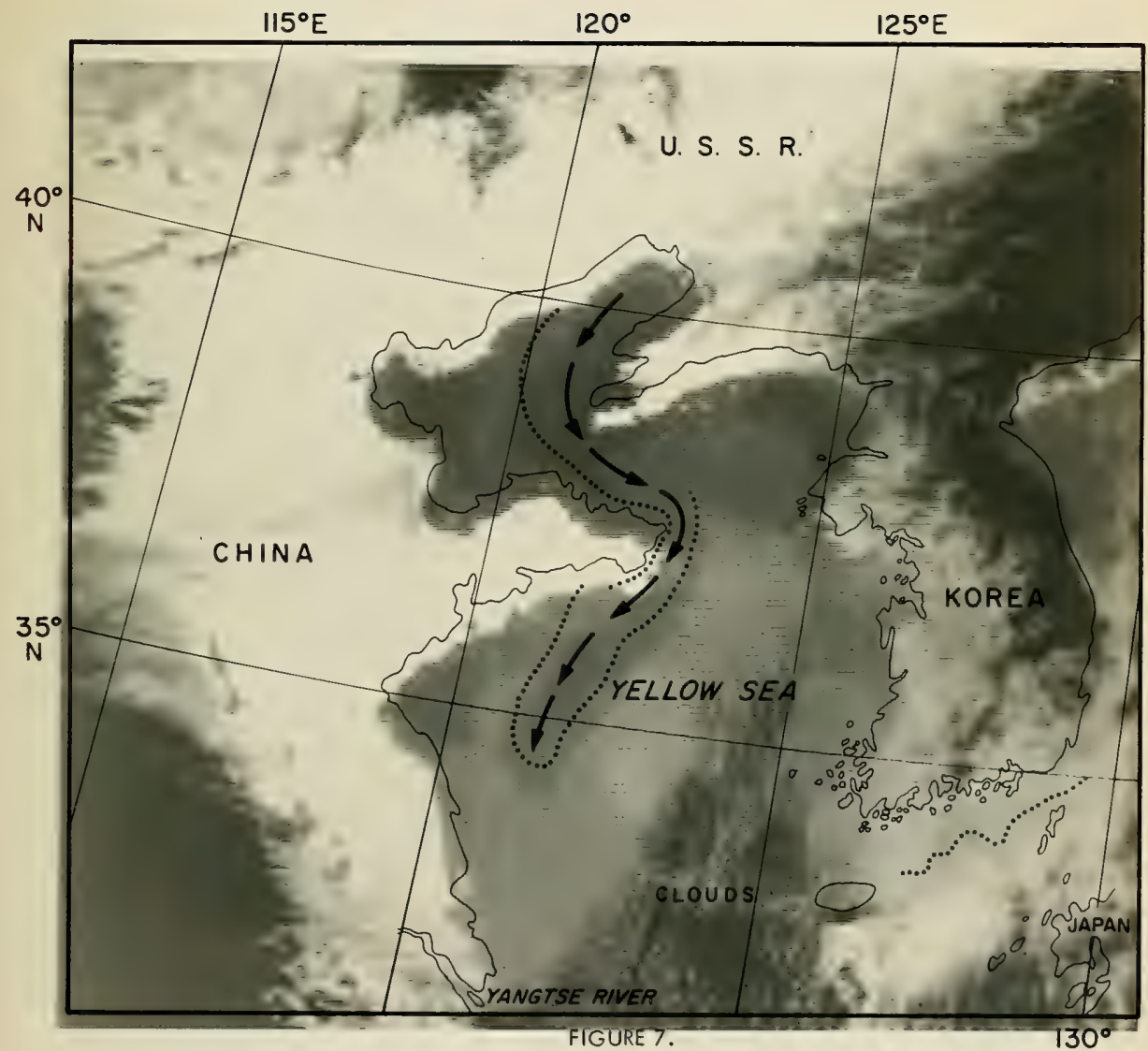


Figure 7 - HRIR data, China Coastal Current in the Yellow Sea. Ascending node, 0309Z, 1 April 1972, 4527/2405, expand center, M11, X4, 291 ${ }^{\circ} \mathrm{K}, 2 \mathrm{n}$.mi . resolution infrared data.

NOTE: The China Coastal Current detected as a tongue of cold water extending from the Gulf of Po Hai south along the western side of the Yellow Sea.

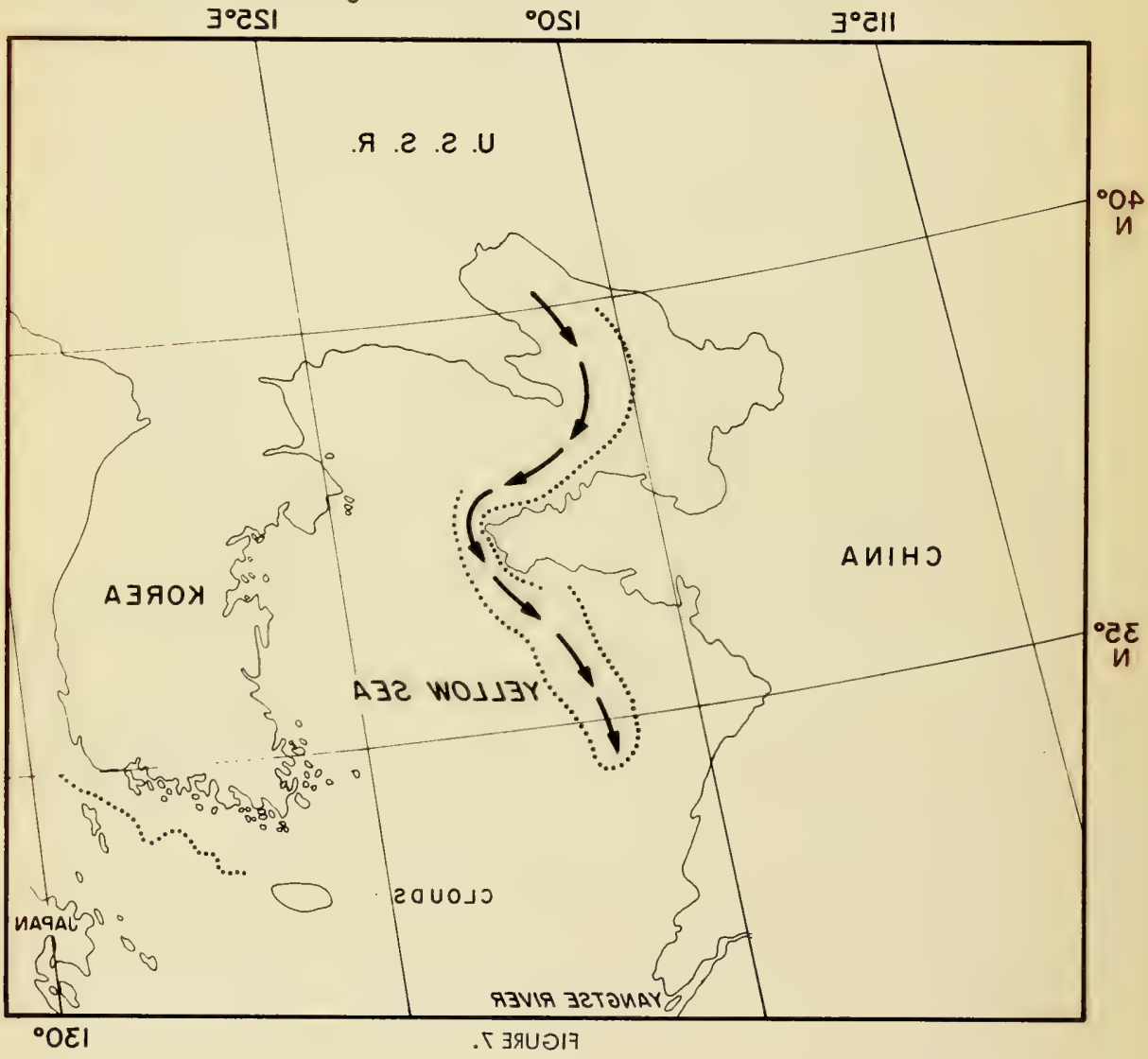




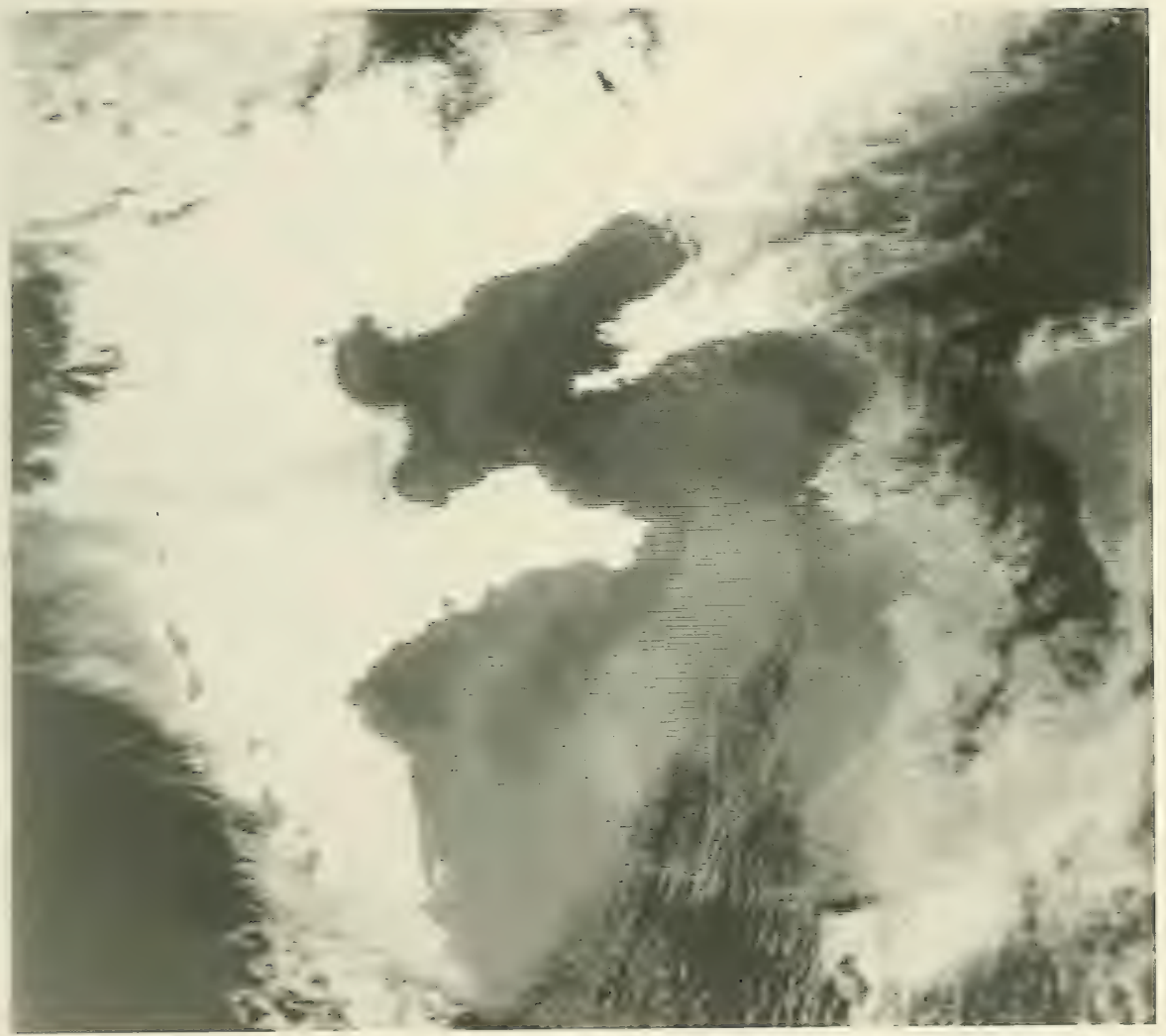


, 
Figure 8 - HRIR data, east China Sea. Descending node, 1201Z, 27 November 1971, $3526 / 4043$, expand center, $M l_{1}, \mathrm{X}_{4}, 298^{\circ} \mathrm{K}, 2 \mathrm{n}$. mi . resolution infrared data. Contact print using film product as a negative.

NOTE: 1. Clouds and land masses displayed black (the latter due to night time terrestrial cooling).

2. Absence of Yellow Sea Water Current seen on fig. 6.

3. Strong oceanic front between Yellow Sea - South Korean waters and the Kurioshio warm waters. 


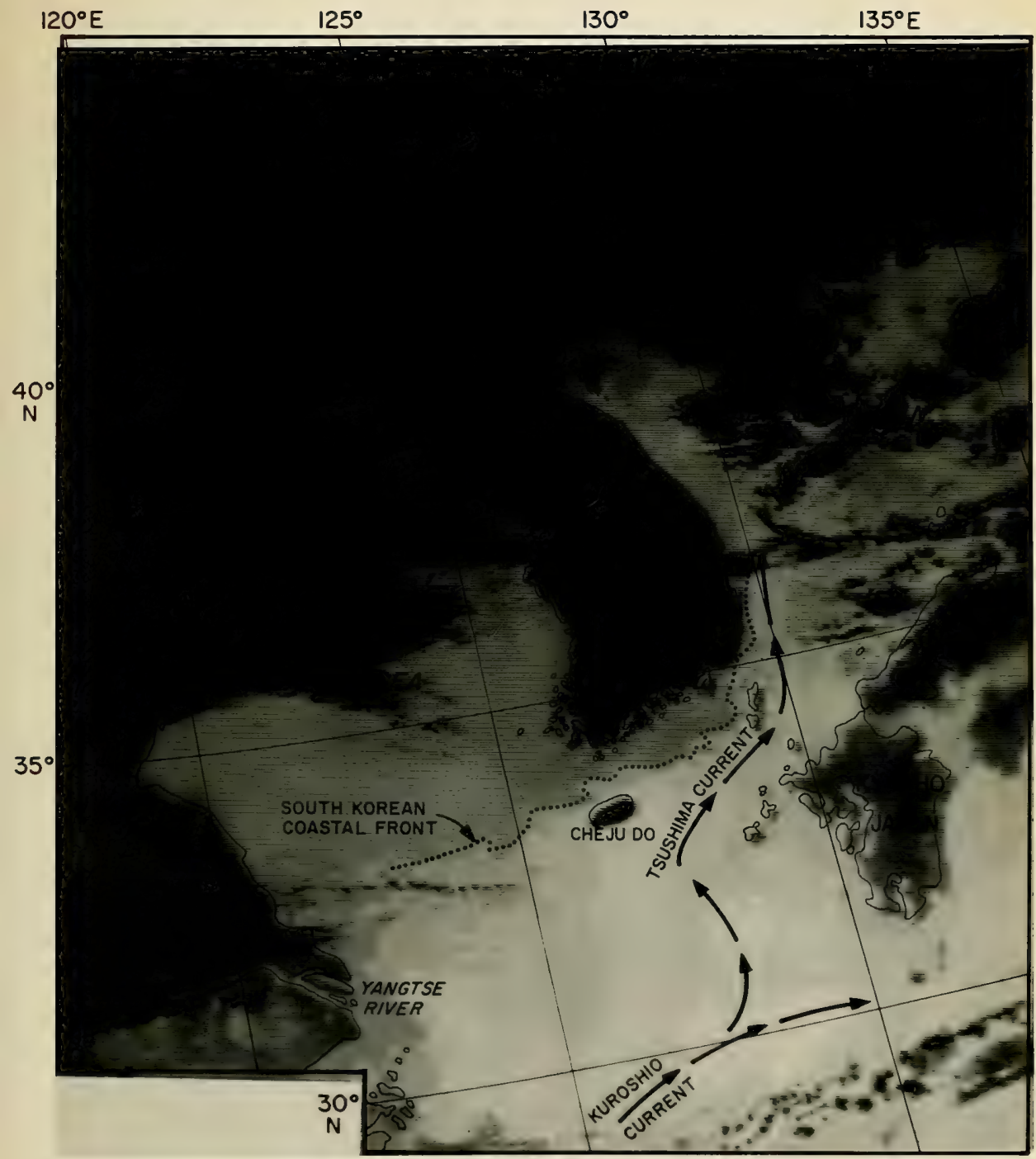

FIGURE 8. 
Figure 8 - HRIR data, east China Sea. Descending node, 1201Z, 27 November 1971, $3526 / 4043$, expand print uping fitm proutur as megative.

NOTE 1. Clouds and land masses displayed black (the latter due to night time terrestrial cooling).

2. Absence of Yellow Sea Water Current seen on fig. 6.

3. Strong oceanic front between Yellow Sea - South Korean waters afid . hee $2 . U$ Kurioshio warm waters.
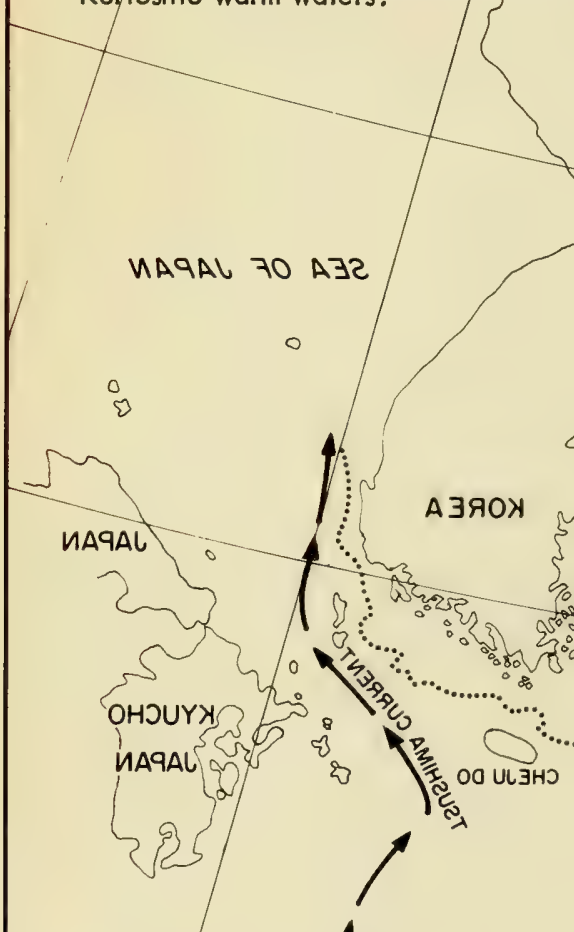


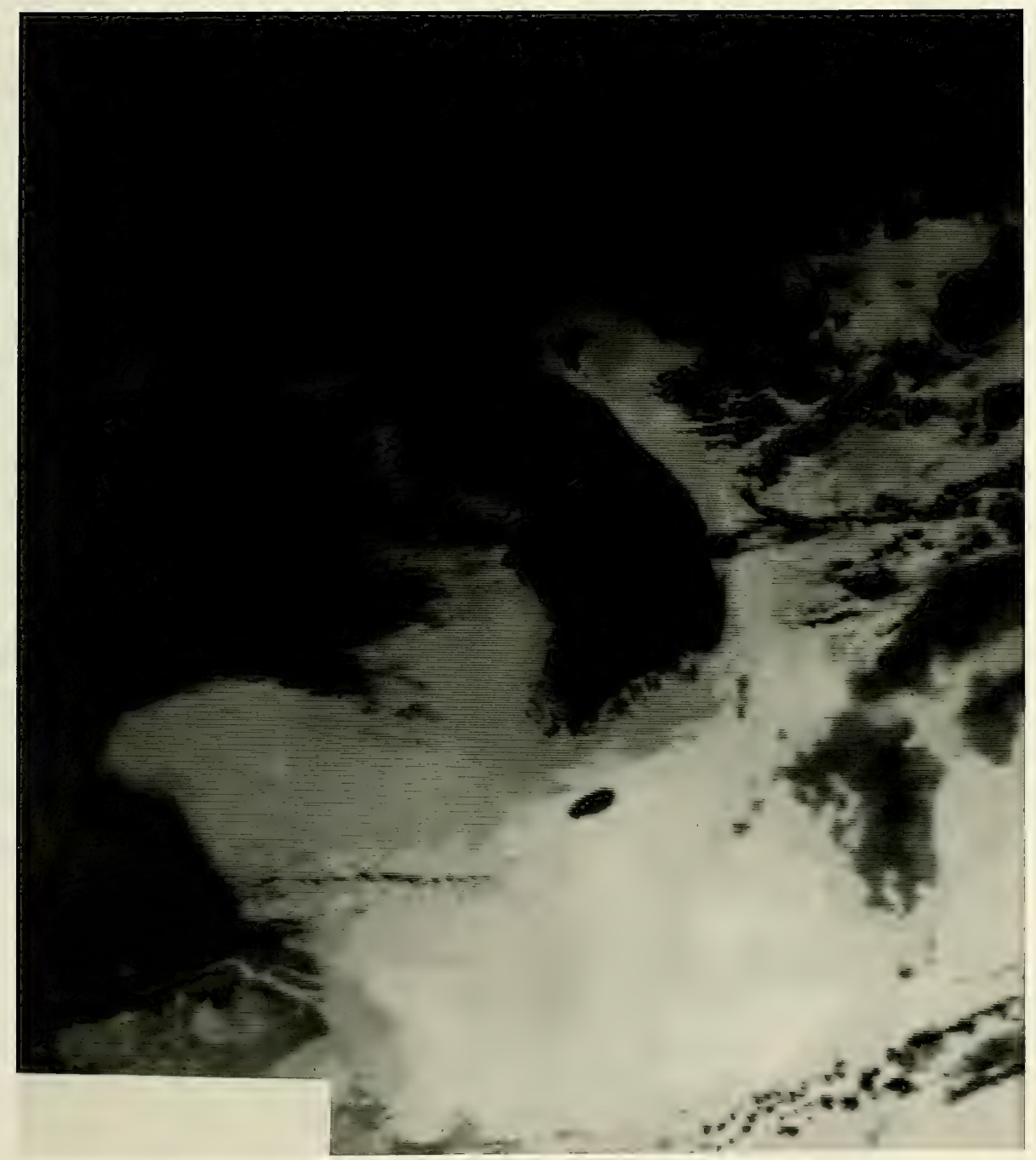



Figure 9 - HRIR data, the Tsushima Warm Current, Korean Peninsula and western Sea of Japan. Descending node, 1255Z, 27 October 1972, 3526/8824, expand right, $\mathrm{Ml}_{1}, \mathrm{X}_{4}$, $295^{\circ} \mathrm{K}, 2 \mathrm{n}$.mi . resolution infrared data. Contact print using film product as a negative. NOTE: 1. Distribution of warm water in Sea of Japan, outlining the flow from each channel of the strait.

2. Strong thermal gradients off south coast of Korea.

3. Hydrodynamic features outlined by sea surface temperatures including:

(a) meanders of the front

(b) cyclonic gyre

(c) small anticyclonic eddy, ENE of Cheju do. 


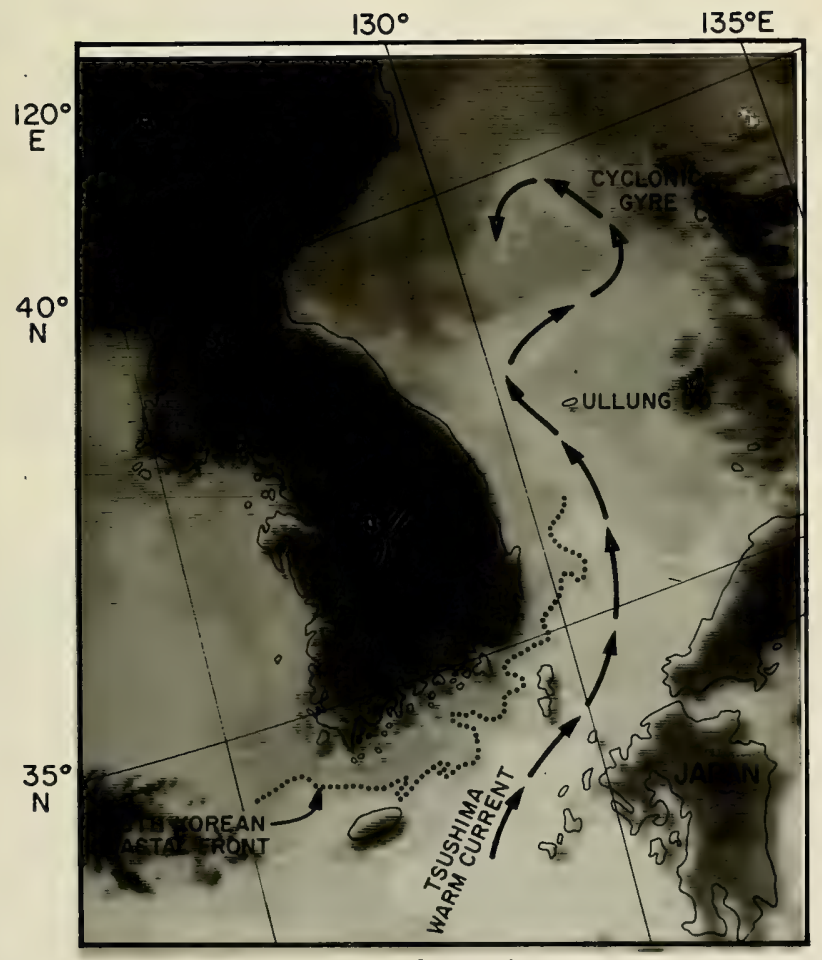

FIGURE 9. 
Figure 9 - HRIR data, the Tsushima Warm Current, Korean Peninsula and western Sea of Japan. Descending node, 1255Z, 27 October 1972, 3526/8824, expand right, $\mathrm{Ml}_{1}, \mathrm{X}_{4}$, $295^{\circ} \mathrm{K}, 2 \mathrm{n}$.mi . resolution infrared data. Contact print using film product as a negative. NOTE: 1. Distribution of warm water in Sea of Japan, outlining the flow from each channel of the strait.

2. Strong thermal gradients off south coast of Korea.

3. Hydrodynamic features outlined by sea surface temperatures including:

(a) meanders of the front

(b) cyclonicy पyry ${ }^{\circ} \mathrm{OEI}$

(c) small an ficytlonic eddy, ENE of Cheiu do.

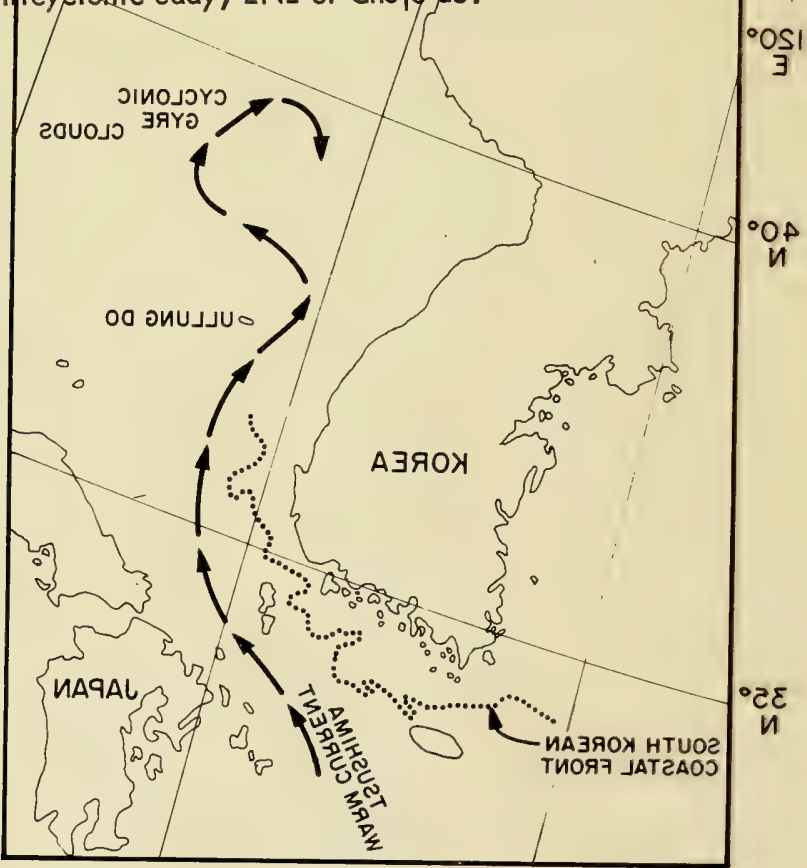

.P 39 ดบ 


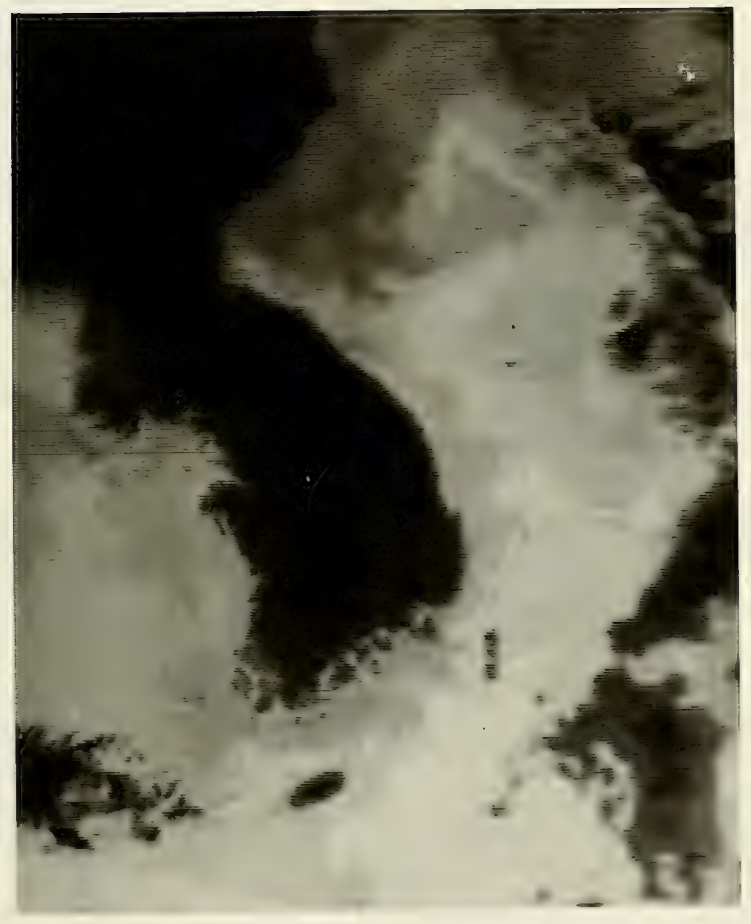





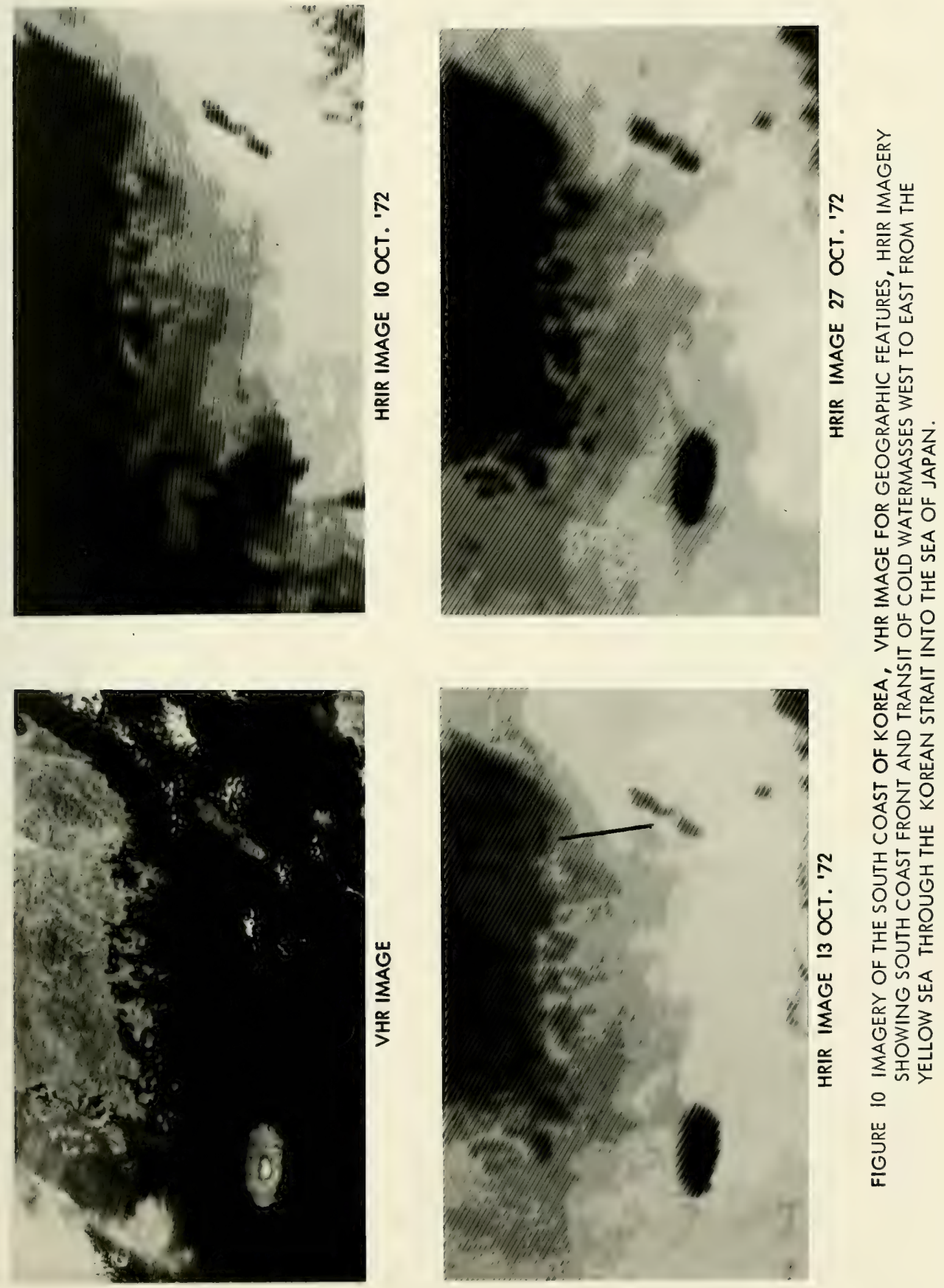



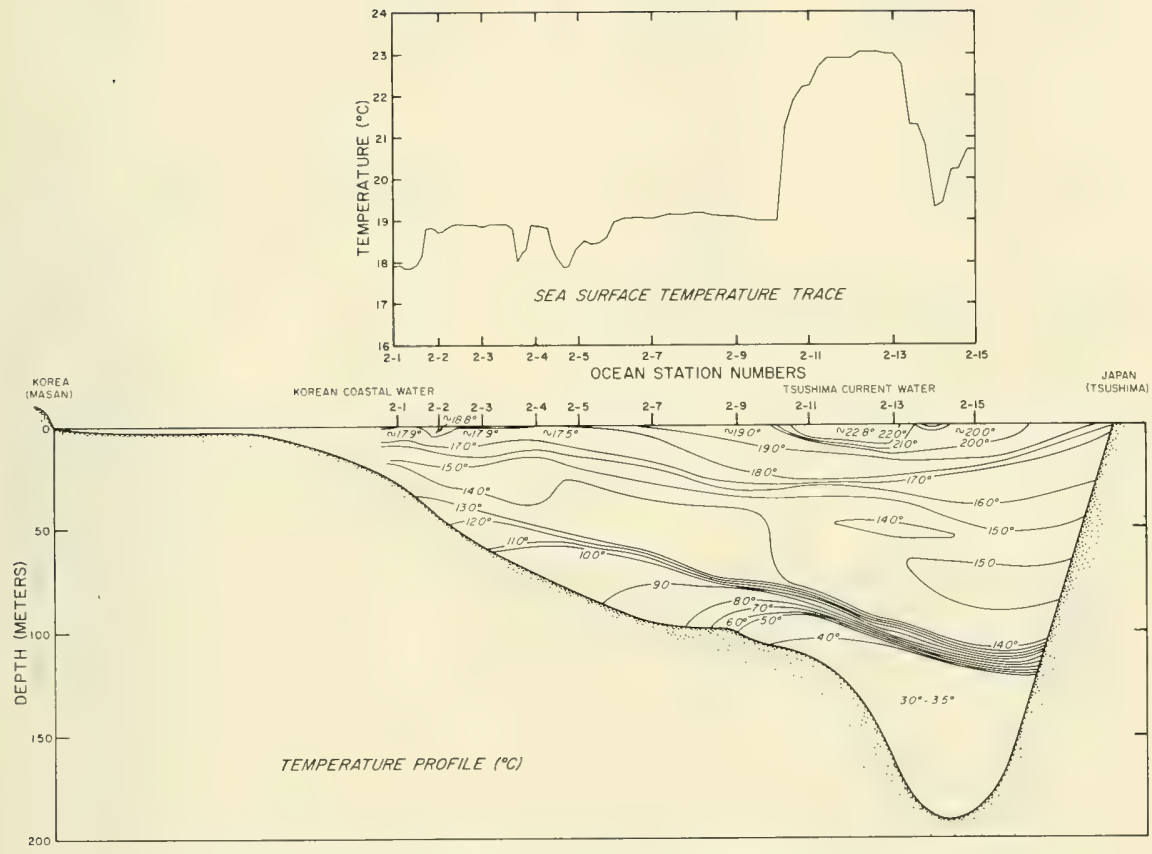

TEMPERATURE PROFILES WEST, CHANNEL, KOREAN STRAIT, 16 OCTOBER 1972

Figure 11 Surface Truth Oceanographic Data (Line of Stations No. 2), Temperature profile obtained by the U.S.N.S. Silas Bent (TAGS-26). Compare with HRIR Image 13 Oct. '72, Figure 10, obtained three days earlier. 


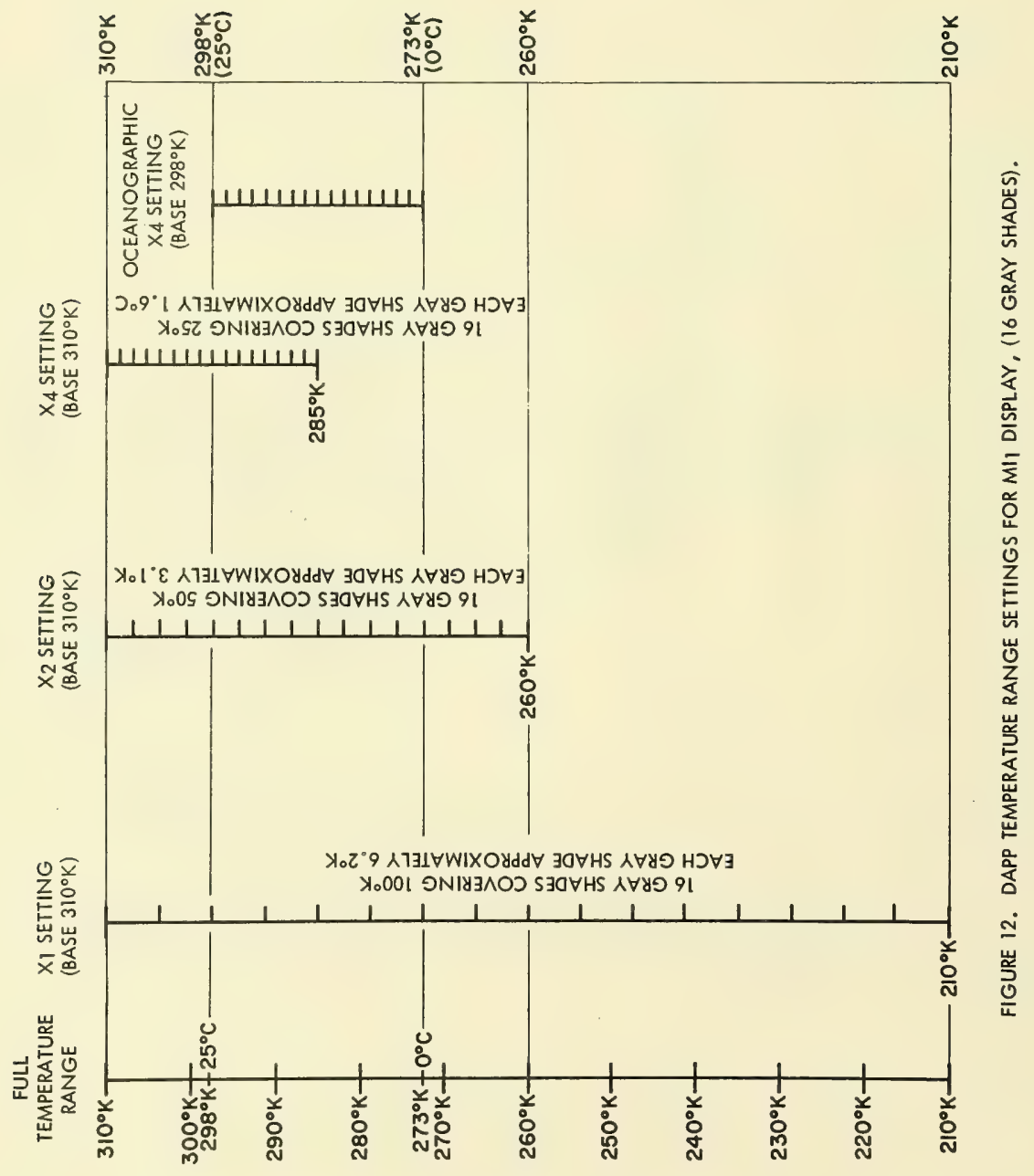




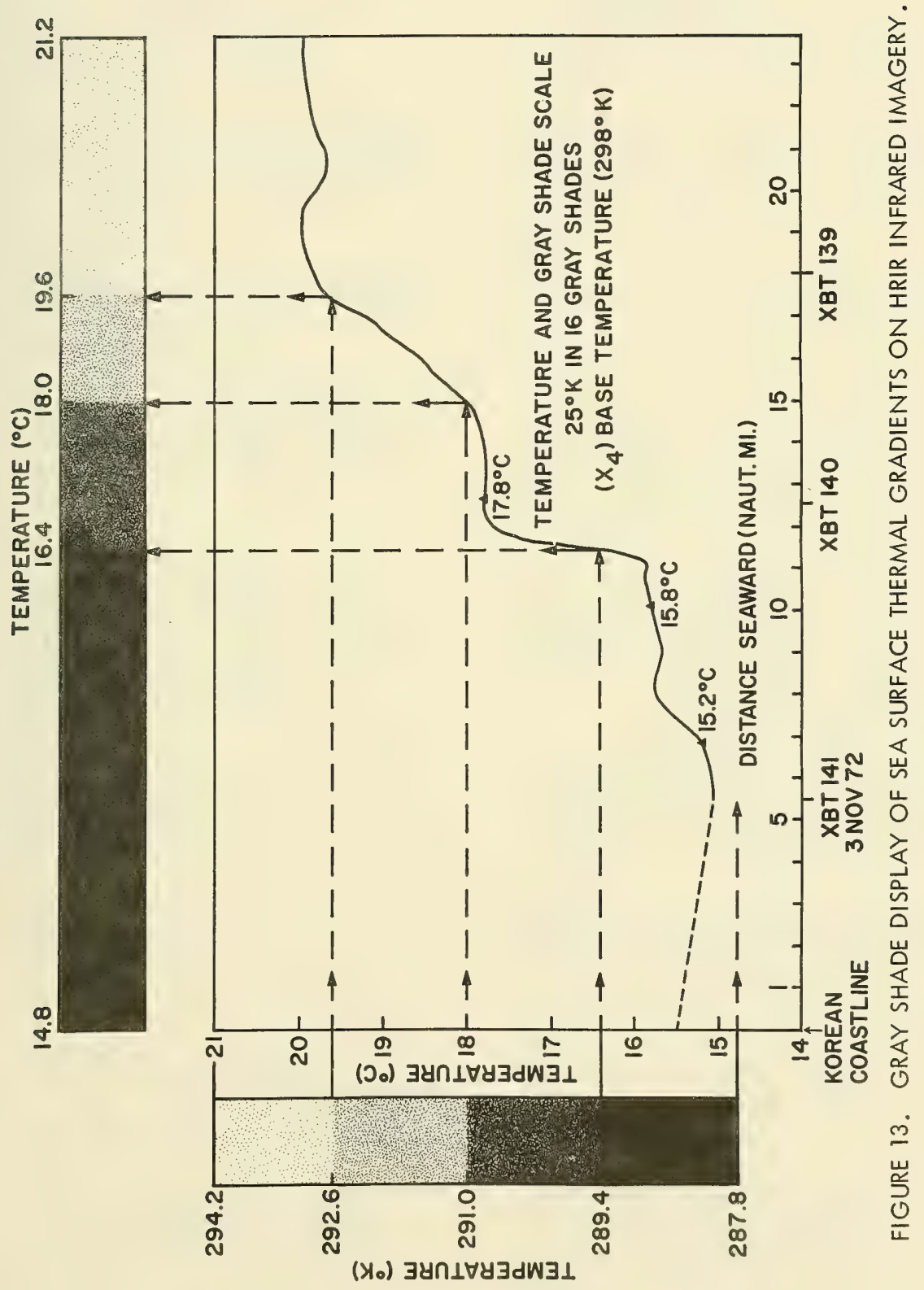



Chief of Naval Research

Geography Programs, Code 414

Washington, D.C. 22217

Director, Naval Research Laboratory

Attention: Technical Information Officer Washington, D.C. 20390

Director

Office of Naval Research Branch Office 219 South Dearborn Street

Chicago, Illinois 60604

Director, Naval Research Laboratory

ATTN: Library, Code 2029 (ONRL)

Washington, D.C. 20390

Chief of Naval Research

Ocean Science and Technology Group

Code 480

Office of Naval Research

Washington, D.C. 22217

Commanding General

Marine Corps Development and

Educational Command

Quantico, Virginia 22134

Oceanographer of the Navy

Hoffman II Building

200 Stovall Street

Alexandria, Virginia 22332

Commander

Naval Facilities Engineering Command

Engineering \& Design

Washington, D.C. 20390

Commanding Officer

Naval Civil Engineering Laboratory

Port Hueneme, California 93041
Defense Documentation Center

Cameron Station

Alexandria, Virginia 22314

Director

Office of Naval Research Branch Office

1030 East Green Street

Pasadena, California 91101

Director

Office of Naval Research Branch Office

495 Summer Street

Boston, Massachusetts 02210

Chief of Naval Research

Asst. for Marine Corps Matters

Code 111

Office of Naval Research

Washington, D.C. 22217

Chief of Naval Operations

OP98T

Department of the Navy

Washington, D.C. 20350

Dr. A.L. Slafkosky

Scientific Advisor

Commandant of the Marine Corps (Code AX)

Washington, D.C. 20380

Librarian

Naval Intelligence, Support Center

4301 Suitland Road

Washington, D.C. 20390

President

Naval War College

Newport, Rhode Island 02840

Commanding Officer

AF Cambridge Research Laboratory

Terrestrial Sciences Laboratory

Laurence G. Hanscom Field

Bedford, Massachusetts 01731 
Director

Coastal Engineering Research Center

U.S. Army Corps of Engineers

Kingman Building

Fort Belvoir, Virginia 22060

Central Intelligence Agency

Attention OCR/DD-Publications

Washington, D.C. 20505

Dr. Carl D. Saver

Department of Geography

University of California

Berkeley, California 94720

Dr. Donn S. Gorsline

Department of Geology

University of Southern California

Los Angeles, California 90007

Dr. Robert L. Miller

Department of Geophysical Sciences

University of Chicago

Chicago, Illinois 60637

Marine Sciences Department, Code 30

Naval Oceanographic Office

Washington, D.C. 20390

Naval Ordnance Laboratory

White Oak

Silver Spring, Maryland 20910

Library

American Geographical Society

Broadway at 156th Street

New York, New York 10032

Officer-in-Charge, Annapolis Division

Naval Ships Research and Development

Center

Annapolis, Maryland 21402
Director

Defense Mapping Topographic Center

ATTN: Code 50200

Washington, D.C. 20315

Commandant

U.S. Coast Guard

ATTN: GECV/61

Washington, D.C. 20591

Assistant Director

For Research and Development

National Ocean Survey

6001 Executive Boulevard

Rockville, Maryland 20852

Director

National Oceanographic Data Center

Washington, D.C. 20390

Naval Academy Library

U.S. Naval Academy

Annapolis, Maryland 21402

Commander

Naval Oceanographic Office

ATTN: Library (Code 36)

Washington, D.C. 20374

Division of Land Research

Commonwealth Scientific and Industrial

Research Organization

P.O. Box 109

Canberra City, A.C.T., Australia

Dr. William W. Wood

Department of Geosciences

Purdue University

Lafayette, Indiana 47907

Defense Intelligence Agency

DIAAP-10A

Washington, D.C. 20301 
Dr. Bernard Le Mehaute

Tetra Tech. Inc.

630 North Rosemead Blvd.

Pasadena, California 91107

Dr. William T. Fox

Department of Geology

Williams College

Williamstown, Mass. 01267

Dr. John C. Ludwick

Institute of Oceanography

Old Dominion University

P.O. Box 6173

Norfolk, Virginia 23508

Naval Oceanographic Office

Code 70

Washington, D.C. 20374

Naval Oceanographic Office

Code 92

Washington, D.C. 20374

Mr. G. Gould

Naval Coastal Systems Laboratory

Panama City, Florida 32401

Dr. G.D. Hickman

Sparcom Inc.

4660 Kenmore Avenue

Suite 1000

Alexandria, Virginia 22304

Dr. Robert J. Byrne

Virginia Institute of Marine Science

Gloucester Point, Virginia 23062

National Lending Library

for Science and Technology

Boston Spa

Yorkshire LS23 780

Great Britian
Dr. Richard A. Davis, Jr.

Department of Geology

University of South Florida

Tampa, Florida 33620

Dr. William S. Gaither

Dean, College of Marine Studies

Robinson Hall, University of Delaware

Newark, Delaware 19711

Naval Oceanographic Office

Code 01

Washington, D.C. 20374

Naval Oceanographic Office

Code 73

Washington, D.C. 20374

Mr. D.T. Hooder

North American Rockwell Corporation

Space Division

12214 Lakewood Boulevard

Downey, California 90241

Chief of Naval Research (Code 460)

Naval Applications and Analysis Division

Office of Naval Research

Arlington, Virginia 22217

Dr. Anthony Orme

Department of Geography

University of California

Los Angeles, California 90024

Officer in Charge

Environmental Prediction Research Facility

Naval Post Graduate School

Monterey, California 93940

Physical and Ocean Sciences Department

U.S. Coast Guard Academy

New London, Connecticut 06320 
Office of Research and Development

IDS $/ 62$

U.S. Coast Guard

Washington, D.C. 20591

Dr. J.A. Dracup

Environmental Dynamics, Inc.

1709 Westwood Boulevard, Suite 202

Los Angeles, California 90024

Dr. Franz E. Anderson

Department of Geography

James Hall

University of New Hampshire

Durham, New Hampshire 03824

Dr. John T. Kud

Henry Krumb School of Mines

Seeley W. Mudd Building

Columbia University

New York, New York 10027

Dr. Carl E. Youngmann

Ohio State University

Department of Geography

1775 S. College Road

Columbus, Ohio 43210

Ministerialrat Prof. Dr. W.J. Aufm Kamp Abtilung RU/FO 111

Bundes Ministerium Der Verteidigung

Postfach 161

D-5300 Bonn, West Germany

Dr. Francis $P$. Shepard

Scripps Institute of Oceanography

La Jolla, California 92038

\section{Establissement}

Principal Du Service

Hydrographique Et Oceanographique De

La Marine

29283 Brest - Cedex
Commanding Officer

U.S. Army Engineering

Topographic Laboratory

ATTN: ETL-ST

Fort Belvoir, Virginia 22060

Dr. Thomas K. Peucker

Simon Fraser University

Department of Geography

Burnaby 2, B.C., Canada

Dr. O.M. Shemdin and M.P. O'Brien

College of Engineering

University of Florida

Gainesville, Florida 32601

Dr. Edward B. Thornton

Department of Oceanography

Naval Postgraduate School

Monterey, California 93940

Director

Amphibious Warfare Board

U.S. Atlantic Fleet

Naval Amphibious Base

Norfolk, Little Creek, Virginia 23520

Dr. Dale F. Leipper

Department of Oceanography

Naval Postgraduate School

Monterey, California 93940

Library, Geological Survey of Canada

Room 350

601 Booth Street

Ottawa 1, Canada

Unit of Coastal Sedimentation

Beadon Road, Taunton,

Somerset, England 
The Library

Department of Geography

University of Cambridge

Downing Place

Cambridge, England

Coastal Studies Institute

Louisiana State University

Baton Rouge Lousisiana 70803

Dr. Robert Dolan

Department of Environmental Sciences

University of Virginia

Charlottesville, Virginia 22903

Office of Naval Research Scientific Liaison Officer

Scripps Institution of Oceanography

La Jolla, California 92038
The Library

Royal Geographical Society

Kensington Grove

London, S.W. 1 England

Dr. Warren C. Tompson

Dept. of Meteorology \& Oceanography

U.S. Naval Post Grad. School

Monterey, California 93940

Commanding Officer

Naval Caostal Systems Laboratory

Panama City, Florida 32401

Commanding Officer

Naval Air Development Center

Warminster, Johnsville, Pennsylvania 18974 

